Urology

Elsevier Editorial System(tm) for European

Manuscript Draft

Manuscript Number: EURUROL-D-17-00952R1

Title: Conducting systematic reviews for underpinning clinical practice guidelines: Experience of the European Association of Urology

Article Type: Review Paper

Section/Category: Statistics in Urology (STA)

Keywords: systematic review; meta-analysis

Corresponding Author: Dr. Muhammad Imran Omar, MBBS, MD, MSC, MMEd, FHEA

Corresponding Author's Institution: European Association of Urology

First Author: Thomas Knoll

Order of Authors: Thomas Knoll; Muhammad Imran Omar, MBBS, MD, MSC, MMEd, FHEA; Steven MacLennan; Virginia Hernández ; Steven Canfield ; Yuhong Yuan; Max Bruins ; Lorenzo Marconi; Hendrik Van Poppel ; James N'Dow; Richard Sylvester; EAU Guidelines Office Senior Associates Group Authorship 


\section{EUROPEAN UROLOGY AUTHORSHIP RESPONSIBILITY, FINANCIAL DISCLOSURE, AND ACKNOWLEDGMENT FORM.}

By completing and signing this form, the corresponding author acknowledges and accepts full responsibility on behalf of all contributing authors, if any, regarding the statements on Authorship Responsibility, Financial Disclosure and Funding Support. Any box or line left empty will result in an incomplete submission and the manuscript will be returned to the author immediately.

\section{Authorship Responsibility}

By signing this form and clicking the appropriate boxes, the corresponding author certifies that each author has met all criteria below (A, B, C, and D) and hereunder indicates each author's general and specific contributions by listing his or her name next to the relevant section.

A. This corresponding author certifies that:

- the manuscript represents original and valid work and that neither this manuscript nor one with substantially similar content under my authorship has been published or is being considered for publication elsewhere, except as described in an attachment, and copies of closely related manuscripts are provided; and

- if requested, this corresponding author will provide the data or will cooperate fully in obtaining and providing the data on which the manuscript is based for examination by the editors or their assignees;

- every author has agreed to allow the corresponding author to serve as the primary correspondent with the editorial office, to review the edited typescript and proof.

B. Each author has given final approval of the submitted manuscript.

$\bigotimes$ C. Each author has participated sufficiently in the work to take public responsibility for all of the content.

$\bigotimes \mathrm{D}$. Each author qualifies for authorship by listing his or her name on the appropriate line of the categories of contributions listed below. 
The authors listed below have made substantial contributions to the intellectual content of the paper in the various sections described below.

(list appropriate author next to each section - each author must be listed in at least 1 field. More than 1 author can be listed in each field.)

_ conception and design $\quad$ Omar, Knoll, N'Dow, Sylvester

_ acquisition of data $\quad$ Omar, MacLennan, Marconi

_ analysis and interpretation of data Omar, Knoll, MacLennan, Hernández, Canfield, Yuan, Bruins, Marconi, Van Poppel, N'Dow, Sylvester, EAU Guidelines Office Senior Associates Group Authorship

_ drafting of the manuscript Omar, Knoll, MacLennan, Hernández, Canfield, Yuan, Bruins, Marconi, Van Poppel, N'Dow, Sylvester

_ critical revision of the manuscript for

important intellectual content Omar, Knoll, MacLennan, Hernández, Canfield, Yuan, Bruins, Marconi, Van Poppel, N'Dow, Sylvester, EAU Guidelines Office Senior Associates Group Authorship

_ statistical analysis None

_ obtaining funding $\quad$ None

_ administrative, technical, or

material support None

_ supervision $\quad \underline{\text { Omar }}$

_ other (specify) $\quad$ None

\section{Financial Disclosure}

$\bigotimes$ None of the contributing authors have any conflicts of interest, including specific financial interests and relationships and affiliations relevant to the subject matter or materials discussed in the manuscript.

\section{OR}

I certify that all conflicts of interest, including specific financial interests and relationships and affiliations relevant to the subject matter or materials discussed in the manuscript (eg, employment/ affiliation, grants or funding, consultancies, honoraria, stock ownership or 
options, expert testimony, royalties, or patents filed, received, or pending), are the following: (please list all conflict of interest with the relevant author's name):

\section{Funding Support and Role of the Sponsor}

$\square$ I certify that all funding, other financial support, and material support for this research and/or work are clearly identified in the manuscript.

The name of the organization or organizations which had a role in sponsoring the data and material in the study are also listed below:

All funding or other financial support, and material support for this research and/or work, if any, are clearly identified hereunder:

The specific role of the funding organization or sponsor is as follows:

Design and conduct of the study

Collection of the data

Management of the data

Analysis

Interpretation of the data

Preparation

Review

Approval of the manuscript

OR

$\bigotimes$ No funding or other financial support was received. 


\section{Acknowledgment Statement}

This corresponding author certifies that:

- all persons who have made substantial contributions to the work reported in this manuscript (eg, data collection, analysis, or writing or editing assistance) but who do not fulfill the authorship criteria are named with their specific contributions in an Acknowledgment in the manuscript.

- all persons named in the Acknowledgment have provided written permission to be named.

- if an Acknowledgment section is not included, no other persons have made substantial contributions to this manuscript.

Muhammad Imran Omar

\section{After completing all the required fields above, this form must be uploaded with the manuscript and other required fields at the time of electronic submission.}


The findings of systematic reviews and meta-analyses are used for clinical decision making, and are integral in developing sound clinical practice guidelines and recommendations. The process of conducting systematic reviews, summarised in this paper, should be followed. 


\begin{tabular}{|l|l|}
\hline Author's name & Affiliation \\
\hline Thomas Knoll (joint first author) & $\begin{array}{l}\text { Department of Urology, Sindelfingen-Boeblingen } \\
\text { Medical Center, University of Tübingen, Sindelfingen, } \\
\text { Germany }\end{array}$ \\
\hline $\begin{array}{l}\text { Muhammad Imran Omar (joint } \\
\text { first author) }\end{array}$ & $\begin{array}{l}\text { Academic Urology Unit, University of Aberdeen, } \\
\text { Aberdeen, Scotland, UK }\end{array}$ \\
\hline Steven Maclennan & $\begin{array}{l}\text { Academic Urology Unit, University of Aberdeen, } \\
\text { Aberdeen, Scotland, UK }\end{array}$ \\
\hline Virginia Hernández & $\begin{array}{l}\text { Department of Urology, Hospital Universitario Fundacion } \\
\text { Alcorcon, Madrid, Spain }\end{array}$ \\
\hline Steven Canfield & $\begin{array}{l}\text { Division of Urology, University of Texas McGovern } \\
\text { Medical School, Houston, Texas, USA }\end{array}$ \\
\hline Yuhong Yuan & $\begin{array}{l}\text { Department of Medicine, McMaster University, Hamilton, } \\
\text { ON, Canada }\end{array}$ \\
\hline Max Bruins & $\begin{array}{l}\text { Department of Urology, Radboud University Medical } \\
\text { Center, Nijmegen, The Netherlands }\end{array}$ \\
\hline Lorenzo Marconi & $\begin{array}{l}\text { Department of Urology, Coimbra University Hospital, } \\
\text { Coimbra, Portugal }\end{array}$ \\
\hline Hein Van Poppel & $\begin{array}{l}\text { Department of Urology, University Hospital } \\
\text { Gasthuisberg, Katholieke Universiteit Leuven, Leuven, } \\
\text { Belgium }\end{array}$ \\
\hline James N'Dow & $\begin{array}{l}\text { Academic Urology Unit, University of Aberdeen, } \\
\text { Aberdeen, Scotland, UK } \\
\text { EAU Guidelines Office, Brussels, Belgium }\end{array}$ \\
\hline Richard Sylvester &
\end{tabular}

\section{EAU Guidelines Office Senior Associates Group Authorship:}

1. Saeed Dabestani

2. Tobias Gross

3. Fabian Hofmann

4. Arjun Nambiar

5. Marc Schneider

6. Thomas Seisen

7. Lisette t'Hoen

8. Thomas van den Broeck

9. Erik Veskimae

\section{$\underline{44354272}$ Words excluding abstract, figures, tables, references and title}

\section{Abstract: 288287 words}




\title{
Key steps in cConducting systematic reviews for underpinning clinical practice guidelines: MethodologyExperience of the European Association of Urology
}

\author{
Abstract: \\ Context: The findings of systematic reviews (SRs) and meta-analyses (MAs) are \\ used for clinical decision making. The European Association of Urology (EAU) has \\ committed increasing resources into the development of high quality clinical \\ guidelines based on such SRs and MAs. \\ Objective: In this paper, we have summarised the process of conducting SRs for \\ underpinning clinical practice guidelines under the auspices of the EAU Guidelines \\ Office.
}

\section{Key messages:}

- The process involves explicit methods and the findings should be reproducible.

- When conducting a SR, the essential first step is to formulate a clear and answerable research question.

- An eExtensive literature search lays the foundation for evidence synthesis.

- Data are extracted independently by two reviewers and any disagreements are resolved by discussion or arbitration by a third reviewer.

- In SRs, data for particular outcomes in individual randomised controlled trials (RCTs) may be combined statistically in a meta-analysis to increase power when the studies are similar enough.

- Biases in studies included in a SR/MA can lead to either an over estimation or an under estimation of true intervention effect size, resulting in heterogeneity in outcome between studies. A number of different tools are available such as Cochrane Risk of Bias assessment tool for RCTs.

- In circumstances where there is too much heterogeneity, or when a review has included non-randomised comparative studies, it is more appropriate to conduct a 'narrative synthesis'. 
- The GRADE tool for assessing quality of evidence strives to be a structured and transparent system, which can be applied to all evidence, regardless of quality.

- A SR not only identifies, evaluates and summarises the best available evidence, but also the gaps to be targeted by future studies.

\section{Conclusion:}

SRs and MAs are integral in developing sound clinical practice guidelines and recommendations.

\section{Patient summary:}

Clinical practice guidelines should be evidence based, and SRs and MAs are essential in their production. We have discussed the key steps of conducting systematic reviews and meta-analyses in this paper. 


\section{Key steps in cConducting systematic reviews for underpinning clinical practice guidelines: MethodologyExperience of the European Association of Urology}

\section{Introduction}

In 1979 Archibald Cochrane, a Scottish doctor, proposed: "It is surely a great criticism of our profession that we have not organised a critical summary, by specialty or subspecialty, adapted periodically, of all relevant randomised controlled trials" [1]. Cochrane was one of the founding fathers of evidence based medicine. He highlighted and advocated the importance of critically summarising the findings of research studies and was passionate about this cause. He designated the systematic review (SR) as a method providing such a summary [1]. Cochrane's vision ultimately led to the development of the Cochrane Collaboration in 1993.

The findings of SRs and meta-analyses (MAs) are used for clinical decision making and are integral in developing sound clinical practice guidelines and recommendations. The European Association of Urology (EAU) has committed increasing resources into the development of high quality clinical guidelines based on such SRs and MAs [2-4]. The Guidelines Office has completed 21 systematic reviews and 32 reviews are ongoing. These high quality systematic reviews are used for making guideline recommendations [5]. Table A (online supplement) summarises Guideline recommendation(s) underpinned by the selected SRs conducted under the auspices of the EAU Guidelines Office. In this paper, we have summarised the process of conducting SRs under the auspices of the EAU Guidelines Office. The process is also graphically illustrated in Figure 1.

What is a randomised controlled trial?

A randomised controlled trial (RCT) is a type of study in which participants are randomly assigned to two or more groups in order to assess interventions. A well designed RCT is adequately powered and follow the principles and recommendations of the CONSORT statement [6].

What is a systematic review? 
A SR identifies, selects, synthesises and appraises studies that meet pre-specified inclusion criteria to answer a research question. The process involves explicit methods and the findings should be reproducible. A SR not only identifies, evaluates and summarises the best available evidence, but also the gaps to be targeted by future studies [7].

\section{What is a meta-analysis?}

In SRs, data for particular outcomes in individual fandomised controlled trials (RCTs) may be combined statistically in a meta-analysis_(MA) to increase power when the studies are similar enough [7]. A meta-analysis MA may thus be able to answer a clinical question which is unanswerable by individual studies due to inadequate power. A MA should not be done outside of the SR setting because it is unlikely that all relevant trials will have been identified and therefore a biased or misleading pooled estimate may result. The term meta-analysisMA was coined by an American statistician, Gene Glass [8].

\section{What is a traditional review?}

A traditional review is usually written by an expert and provides a summary or an overview of a topic. Unlike a SR, the topic of a traditional review is often broad and less precisely defined. The methods used to conduct traditional reviews are not standardized. The search strategy is usually not stated, the review is confined to well-known articles [9], and the author's personal beliefs may influence the overall conclusion [10]. If MAmeta-analysis is attempted in this situation, an exaggerated and spuriously precise estimate may be obtained and treated with greater credibility than it is due. The main features of SRs are covered throughout this report and the key differences between a SR and traditional review are summarised in Table 1.

\section{Formulating a clear, well-designed research question and writing a review protocol}

When conducting a SR, the essential first step is to formulate a clear and answerable research question. This clarifies the objectives and the study inclusion and exclusion criteria. A straightforward way to do this is to break the question down into constituent parts using the PICO framework, which stands for Participants, Intervention, Comparator and Outcomes [11]. 
It is necessary to be transparent and explicit about which populations, intervention, comparator and outcomes are to be included or excluded. This is important for not only designing the search strategy but is also helpful for systematic reviewers who do not necessarily have in-depth clinical knowledge on the topic. Furthermore, it serves as a blueprint to inform study screening and data extraction. To illustrate: 'Should I perform partial nephrectomy on a patient with kidney cancer? is a meaningful question, particularly for urologists. However, it is vague and not informative for deciding which studies should be included. A more scientific way for phrasing this question is: 'In patients with localised renal cell carcinoma (P), how effective is partial nephrectomy (I), when compared with radical nephrectomy (C), in improving overall survival (0)?'

Of course, more clinically or methodologically justifiable detail will need to be provided to define limits on age, disease stage, which approaches to partial and radical nephrectomy are included, which other (secondary) outcomes should be included and search date cut-offs. The types of study designs to be included should be specified. Cochrane SRs are traditionally confined to evidence from RCTs. However, it is not always ethical to randomise participants for comparing interventions and observational studies play a crucial role in this scenario.

SRs should be protocol driven and prospectively registered in a database, such as PROSPERO [12] or the Cochrane Library, to help counter publication bias and selective outcome reporting by giving a permanent record of the a priori methods. PROSPERO is a database maintained by the University of York. PROSPERO provides a free registration and publication of systematic review protocols and is available at the following link: https://www.crd.york.ac.uk/PROSPERO/. Registration of protocols also means that others can see if a review is currently underway and work is not duplicated. Crucially, in addition to the PICO elements, a protocol outlines what actions will be taken in which circumstances, such as how particular types of data will be handled in the analyses, the conditions under which metaanalyses or narrative synthesis will be undertaken, which subgroups will be analysed, and how risk of bias (RoB) will be assessed.

\section{Literature search}


Extensive literature search lays the foundation for evidence synthesis. With increasing numbers of published research reports and numerous bibliographic databases, it is challenging to efficiently identify relevant studies, especially when research topics are complex and study designs are not limited to RCTs.

Conducting a literature search to identify relevant reports from databases and other resources requires rigorous search techniques. When designing searches, high sensitivity and high specificity should be aimed for. However, no search strategy is $100 \%$ perfect; high sensitivity may result in a huge number of irrelevant records and there is always a trade-off. It is advisable to involve an information scientist for designing search strategies.

Literature searches for SRs should involve at least two bibliographic databases and be as extensive as possible in order to identify all relevant studies and increase the generalisability of the results. According to MECIR (Methodological Expectations for Cochrane Intervention Reviews), Cochrane Central Register of Controlled Trials (CENTRAL), MEDLINE, (and EMBASE and Cochrane Review Group's Specialized Register when available) are the minimum databases to be searched for a Cochrane SR [13]. Most published SRs now search at least MEDLINE, EMBASE and Cochrane library databases. Databases relevant to the topic of the review (e.g. CINAHL for nursing-related topics), national and regional database and subject specific databases should also be considered. Trials registers such as ClinicalTrials.gov, the WHO International Clinical Trials Registry Platform (ICTRP) portal and other sources (e.g., pharmaceutical industry and regulatory agencies websites) should be searched for unpublished and ongoing studies. Other sources include dissertations, theses, conference abstracts and proceedings, and grey literature (information produced in electronic and print formats not controlled by commercial publishing) databases. Searching the bibliographies of identified relevant studies and previous SRs on the same topic is a good approach for reducing the chance of missing relevant studies. Study authors and organizations should be contacted for missing information on un-published or ongoing studies [7, 13].

Content experts are very important in designing advanced search strategies [7]. By working closely with information specialists, they can assist with identifying search concepts, and suggest key words as well as key references, while revising and 
improving preliminary searches. Too many different search concepts should be avoided. Sometimes, some concepts (e.g. outcomes) may not be well described in the title or abstract of an article and are often not well indexed with controlled vocabulary terms; it might be better to search only for the population and intervention. However, a broad range and wide variety of search terms should be combined with "OR" within each concept. Both free-text words (including spelling variants, synonyms, related terms, opposites, plurals, acronyms, truncations, wildcards, and proximity operators) and appropriate subject headings should be used (e.g. MeSH and EMTREE). Ensure the Boolean operators "AND", "NOT" and "OR" are used correctly. An example of search strategy, along with explanation, is presented in Figure 2. Strategies must be translated for every database and each interface (e.g. PUBMED and OvidSP are two different interfaces for the same database MEDLINE). Specially designed high sensitivity and tested filters can be used when appropriate. There is no need to use an RCT filter when searching CENTRAL because all the records are thoroughly and correctly indexed. Applying publication date, publication format or language restrictions in the search strategy should be justified and included in the report [7]

The search strategy should be documented and reported transparently in the protocol and in the review. It is necessary to report the sources searched (databases and interfaces), dates and limits, and the numbers found from each source [14, 15]. Key search terms can be reported in the methods section. The full search strategies for one or more electronic databases can be submitted as an appendix and published as supplementary files available online to readers.

\section{Abstract and full text screening}

After the literature search has been conducted, the list of retrieved abstracts is screened for studies that may be eligible for inclusion. Abstract screening is performed using an a-priori developed study screening form. This form contains the inclusion and exclusion criteria for each PICO element as reported in the study protocol. Following this form will lead to the decision whether to exclude or include the abstract. In case no decision can be made based on the information in the abstract, it will be marked as 'unclear'. Unclear abstracts are included at this stage, as it requires full-text retrieval and review to make the final decision. Abstract screening must be performed independently by (at least) two reviewers. The 
combined results will subsequently be reviewed for disagreements, and a third independent reviewer can be consulted for resolving conflicts.

Full-text screening follows the same principles as abstract screening. A difference, however, is that full-text papers cannot be marked as 'unclear' but require a definitive decision whether to include or exclude the study. Also, for excluded full-text papers, reviewers must keep track of the reason for exclusion. Upon completion, the final number of included and excluded studies (with the reason for exclusion) is reported in the PRISMA flow diagram as illustrated in Figure 31 .

\section{Data extraction from included studies}

One of the most important and time-consuming parts of a SR is data extraction. Data are extracted independently by two reviewers and any disagreements are resolved by discussion or arbitration by a third reviewer [16]. Table 2 summarizes the key information that should be extracted from the studies included in a SR. Each review question is unique and therefore requires development of a separate form. A pilot tested electronic or paper version of the data extraction form includes entries for study characteristics along with relevant results and RoB assessment. The data extraction form should first be piloted on 2 to 3 studies.

The setting and timing of the study, participant and disease characteristics (such as age, gender, comorbidities, diagnostic criteria, staging, and prognostic factors) that may influence intervention effects or external validity should be collected. Relevant information on interventions include surgical techniques, drug doses and frequency, or routes of delivery. It is important to clearly pre-decide the outcome measures that will be collected in terms of their definition (e.g. measurement method, scale, and threshold), timing and unit(s) of measurement. This is crucial as many outcomes may be reported using multiple definitions (e.g. Biochemical Recurrence after Radical Prostatectomy), measurement scales (e.g. multiple urinary symptom questionnaires to access the severity of urinary incontinence), measurement method (e.g. healthy parenchymal volume loss after partial nephrectomy measured by CT volumetric analysis or estimated by surgeon) or different points in time (e.g. cancerspecific survival at $1 \mathrm{y}, 5 \mathrm{y}, 10 \mathrm{y}$ ). Standardised sets of outcomes, known as 'core outcome sets' represent the minimum that should be measured and reported in all clinical trials of a specific condition making it easier for the results of trials to be 
combined [17]. The numerical data required for meta-analysisMA are not always available and sometimes other statistics or graphical information can be collected and converted into the required format.

\section{Risk of Bias Assessment}

Biases in studies included in a SR can lead to either an over estimation or an under estimation of true intervention effect size, resulting in heterogeneity in outcome between studies.

\section{$\underline{\text { Randomized Controlled Trials }}$}

In SRs of RCTs, the RoB in each study is assessed for each outcome using the domains (judged as either low, high, or unclear) in the Cochrane Collaboration's RoB Tool $[7,18]$ :

- Selection bias, which includes random sequence generation bias and allocation concealment bias.

- Performance bias due to knowledge of the allocated intervention by study personnel and participants.

- Detection bias in assessing the outcome due to knowledge of the allocated intervention.

- Attrition bias due to incomplete data and exclusion from analyses.

- Reporting bias due to selective outcome reporting.

- Other sources of bias.

RevMan is then used to create a RoB summary graph to visually illustrate the RoB (low, high, or unclear) for each domain in each study [19]. A draft version of a revised tool to assess the RoB in RCTs (RoB 2.0) has recently been proposed [20].

\section{Non-randomized Comparative Studies}

Potential biases are greater in non-randomized comparative studies (NRCS) than for RCTs due to the high risk of confounding. NRCS are thus always considered to be at high risk of selection bias.

In addition to assessing the above domains for RCTs, a maximum of the five most important confounders should be pre-specified. For each outcome, an assessment is 
made of (1) whether the confounder was considered, (2) whether its distribution was balanced, and if not then (3) whether it was controlled for in the analysis.

This information is used to reach an overall decision about the RoB for each confounder and each outcome. The RoB summary graph can also include the additional confounder information.

Recently, ROBINS-I, a tool for assessing risk of bias in non-randomised studies of interventions has been published. This tool is not yet tested within the EAU [21].

\section{Single Arm Studies}

In SRs of single arm case series, five aspects are considered:

1. Was there an a priori protocol?

2. Was the total population included or were study participants selected consecutively?

3. Was outcome data complete for all participants and any missing data adequately explained/unlikely to be related to the outcome?

4. Were all pre-specified outcomes of interest and expected outcomes reported?

5. Were primary benefit and harm outcomes appropriately measured?

If the answer to all 5 questions is 'yes', the study is at 'low' RoB. If the answer to any question is 'no', the study is at 'high' RoB.

QUADAS-2 is used for assessing RoB in diagnostic test accuracy SRs [22] while QUIPS is used for prognostic factor SRs [23].

\section{$\underline{\text { RoB assessment process }}$}

Two reviewers independently assess the RoB in each study when extracting data. A third reviewer acts as arbitrator. If the RoB is unclear in any domain, an attempt is made to obtain the study protocol or to contact the study authors. RoB summary graphs are created with separate graphs for each of the three different study types. Biases are described in the SR report, emphasizing areas of concern and the possible effect of bias in interpreting the results [18].

Meta-analysis or Narrative synthesis (including sub-group analyses, assessment of heterogeneity and publication bias) 
Combining information from different studies included in a SR is known as evidence synthesis. Depending on the homogeneity of the populations, interventions, outcome definitions and measurements in the included studies, the evidence synthesis may be narrative or quantitative.

MAMeta-analysis is feasible when more than one RCT reporting the same outcome is identified [24]. MAMeta-analysis_-provides an overall estimate of the effect of the treatment or the intervention analysed. The effect of the treatment refers to the differences in outcomes found between an intervention and comparator. This effect, along with the precision of the estimate, needs to be extracted from all the individual studies, so that the consistency in the direction and magnitude of effect across studies can be assessed [25].

However, before meta-analysing data, a detailed assessment of the included studies is crucial to decide whether a meta-analysisMA of the results is not only feasible but also sensible. First, the internal validity and precision of the included studies will directly impact the quality of a meta-analysisMA. If the included studies are biased, underpowered, or the individuals estimates inconsistent, then performing a metaanalysis $\underline{M A}$ can potentially give a spuriously precise and often meaningless summary statistic.

One should take into account that the studies included in a SR will inevitably differ. Despite clearly defined eligibility criteria, differences in the included studies will exist with regards to natural variation in the populations and fidelity to the interventions. Those variations are known as heterogeneity [26]. There are three main types of heterogeneity (1) Clinical heterogeneity, which refers to variations in the populations, interventions or the way in which the outcomes were assessed. (2) Methodological heterogeneity, which refers to differences in study design and reporting biases. (3) Statistical heterogeneity, which refers to variability in treatment effects due to the way the data are analysed and reported in each study.

There are several ways to investigate heterogeneity. First, heterogeneity can be assessed by visual inspection of the forest plots. Poor overlap among confidence intervals may indicate statistical heterogeneity. The $\mathrm{Chi}^{2} \mathrm{Q}$ statistic assesses the degree to which the individual study estimates of effect size differ from the overall estimate while the $I^{2}$ statistic is an estimate of the percent of variation attributable to 
heterogeneity, i.e. the ratio of true heterogeneity to total observed variation $[7,26$, 27]. An $I^{2}$ greater than $50 \%$ is considered substantial. Meta-analysisMA and the estimation of an overall summary effect in the presence of significant heterogeneity may be misleading, but several options can be considered in this scenario. Some heterogeneity may be explained by the intervention having different effects in, for example, older populations or at higher doses of a drug. In such instances, the stratification of studies according to their characteristics or subgroup analyses in specific patient populations may be done to explore heterogeneity or to try to answer specific questions, however this may not be possible without individual patient data. Such analyses should be regarded as exploratory and the results must be interpreted with caution $[28,29]$. They should be planned at the protocol stage rather than in the light of the results, otherwise the conclusions may not be reliable [30].

Publication bias should also be considered. Trials showing statistically significant results are more likely to be published than those with negative findings [31]. They are also more likely to be published quickly, in more than one place, in English, in high impact, indexed journals and cited by others [7]. Funnel plots, which plot the effect estimate of individual studies against the size of the study, may be used to identify the publication bias but these should only be used when there are at least 10 studies in the meta-analysis $\underline{M A}$.

In circumstances where there is too much heterogeneity, or when a review has included NRCS, it is more appropriate to conduct a 'narrative synthesis' [7, 32, 33]. This is a theory driven and iterative approach for summarising and imposing structure on the results of the included studies. Four main stages are involved:

1. Develop a theory of how the intervention works, why, and for whom

2. Develop a preliminary synthesis of the findings of the included studies

3. Explore relationships within and between studies

4. Assess the robustness of the synthesis [33]

Essential activities include tabulating and describing the key baseline characteristics and results of individual studies. Then studies with similar populations, intervention and outcome measurement characteristics can be grouped together and then further grouped with regards to the direction and magnitude of the results. The results may then be interpreted critically with regards to the theory, considering also the RoB and 
potential confounders within and across the included studies to make statements about the quality of the evidence about the intervention. Figure $\underline{42}$ illustrates a decision flow diagram when to meta-analyse data or to use narrative synthesis.

\section{Quality of evidence (GRADE)}

The GRADE (Grades of Recommendation, Assessment, Development and Evaluation) Working Group, in response to the need for an improved system of evidence quality assessment, developed a tool in 2000 using input from health professionals, researchers and guideline developers around the world [34]. The GRADE tool for assessing quality of evidence strives to be a structured and transparent system which can be applied to all evidence, regardless of quality. There are a few basic tenets of evidence quality using GRADE [35]. The final quality assessment, which applies to the body of evidence (all studies included in the SR) is reported as one of four possible levels: high, moderate, low or very low. Foremost is that RCTs start out as high quality and that non-randomized (observational) studies start out as low quality. According to GRADE, there are five factors which can affect overall evidence quality which starts out high in a negative way, and three factors which can affect quality which starts low in a positive way [36].

Starting at potentially high quality, RCTs are susceptible to certain biases which, when present, can raise doubt in the study findings. Once summarized, these inherent study elements inform the overall RoB of all the studies included in the analysis. This overall study "risk of bias" is the first of the five "negative" factors used in GRADE to assess the overall quality of the evidence. Next are items which assess how the overall evidence is represented and balanced. "Inconsistency" examines the direction of different study results. For example, if one study shows an intervention is helpful while another does not, they are inconsistent. "Indirectness" examines the details of exactly what is compared in the various studies being reviewed. If studies use different intervention methods, they may be indirectly comparing results. "Imprecision" examines the margin of potential error within all combined studies. All of these factors may raise doubts about the validity of the combined data, especially when trying to use it for a recommendation. Finally, if small studies showing negative results are missing from the literature, potential "publication bias" becomes a concern as well $[34,36,37]$. 
If observational studies are incorporated in a SR, inherent study bias is already assumed and the overall evidence quality starts out as "low". However, if the combined effect size of the outcome is undeniable ("large" > 50\%, "very large" > $75 \%$ ), if there is an obvious dose response seen, or if there is evidence that the plausible confounders would diminish the demonstrated effect, the quality of this evidence can actually be raised. Evidence from observational studies that has been downgraded for any reason (as explained above) should not be upgraded. The process of assessing the quality of evidence is summarised in Figure $\underline{5}$. Ultimately this process strives to be structured, systematic, and transparent.

\section{Incorporation of systematic review results in Guidelines}

The aim of the EAU Guidelines is to assist practicing clinicians in making informed decisions in different clinical situations, taking the highest quality scientific data, their patient's personal circumstances, values and preferences into account. The development of the Guidelines is a core activity of the EAU as part of their educational efforts and the available guidelines cover most of the urological field. A transparent production process and continuous updating are assured to ensure that these guideline documents are, and remain, of high value to their users. High quality SRs are a superb source of data when composing clinical guidelines. The EAU Guideline Office made a major step forward when deciding not only to use such SRs for the guidelines, but to also perform their own SRs based on PICO questions identified and defined by the expert panels. The SRs are performed in a standardized manner, following Cochrane methodology, with inclusion of expert urologists, associates, methodologists, statisticians and medical librarians. The results are published in peer-reviewed journals and are included in the annual updates of the specific guideline.

\section{Recent technological advancement}

The process of conducting a SR is laborious. However, a number of technological advancements have made the process of conducting a SR easier. For example, software which can read graphs such as survival curves and help with their interpretation are available. Plot Digitizer is one such tool and is freely available online [38]. In addition, RevMan now contains an online calculator for imputing missing data. The Cochrane Collaboration has continually adopted technology to 
simplify the process of conducting SRs. As part of The Cochrane Collaboration's Strategy to 2020 initiative, the Informatics and Knowledge Management section is working on a number of projects such as the PICO annotation project and the Linked Data project. A number of other organizations have also developed tools for making the process of conducting SRs more efficient. Some of the available tools are: Abstrackr, Covidence, DistillerSR, Eppi-Reviewer 4, EROS, ExaCT, Rayyan, RevMan HAL, SUMARI and TrialState SRS 4.0 [39]. Two of these tools are recommended by The Cochrane Collaboration (Covidence and Eppi-Reviewer). These packages can speed up the review process and some assist by semiautomating key SR tasks.

\section{Future of systematic reviews}

Projects like AllTrials will provide access to research data [40]. This will eventually reduce research wastage and will provide a source of 'Big Data'. The raw data from individual trials can be used for Individual Patient Data meta-analysisMA, the gold standard. Text mining technologies are also explored which may reduce the reviewers' time through automating the key tasks such as citation screening. Data extraction with data mining technology, data-tagging, and translations have also been explored [41]. Automation of review process tasks could help us to achieve "living systematic reviews" i.e. SRs which are continuously updated incorporating relevant data as it becomes available. The use of technology in the SR process will reduce time from the completion of a study to incorporating the findings within the review, and evidence will be more reliable and readily available [41]. 


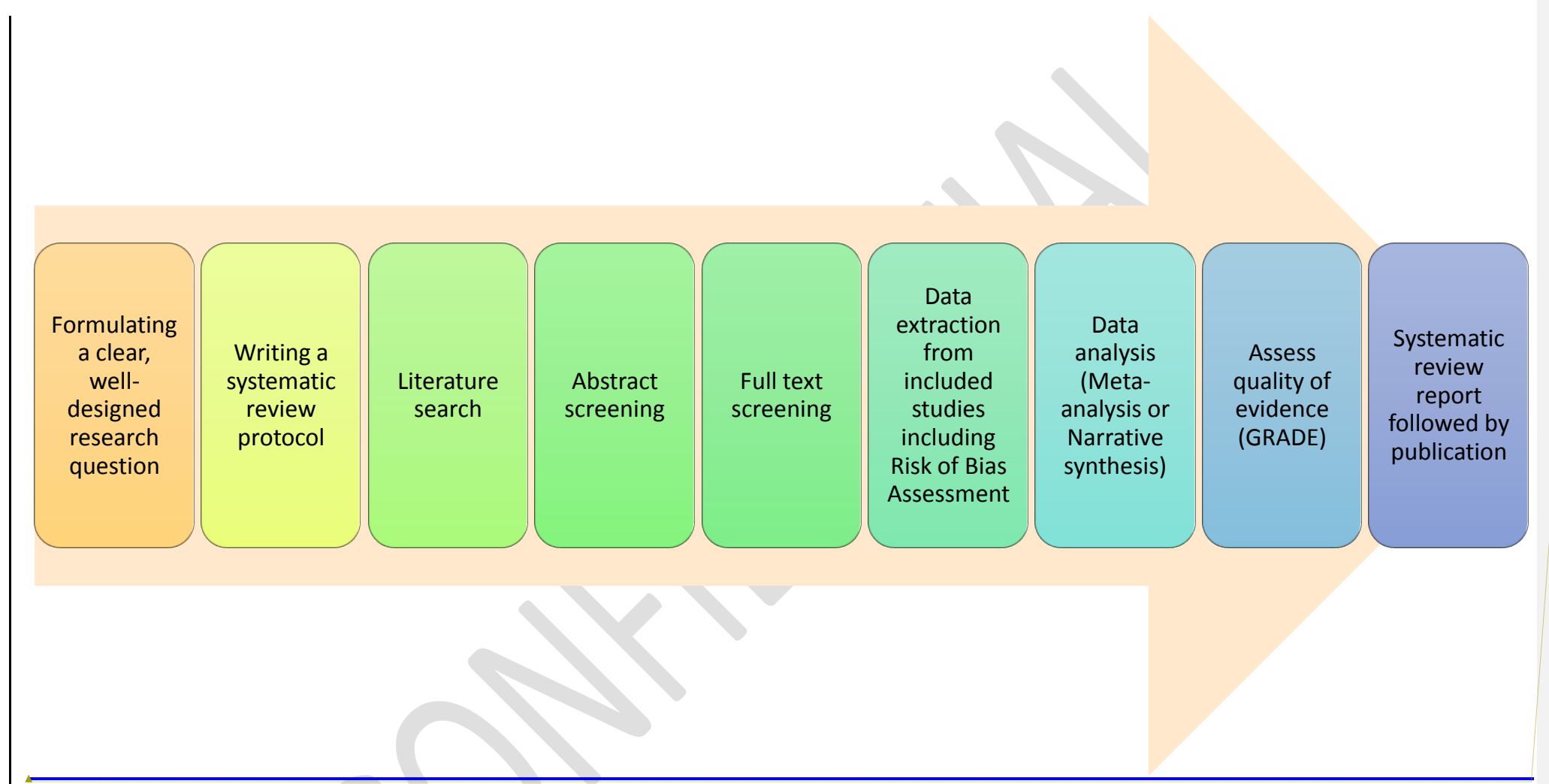

Formatted: Font: (Default) Arial, 12 pt, Bold

Figure 1: The process of conducting systematic review

Page $\mathbf{1 7}$ of $\mathbf{3 0}$ 


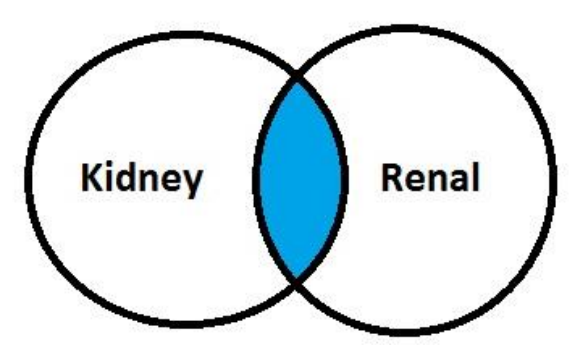

AND

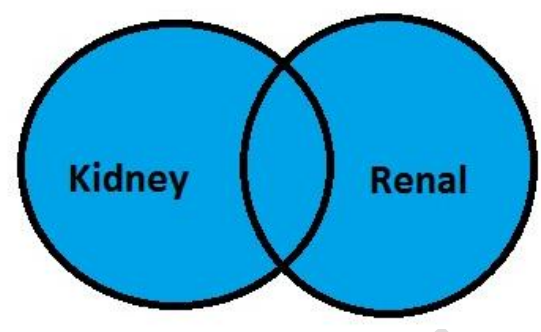

OR

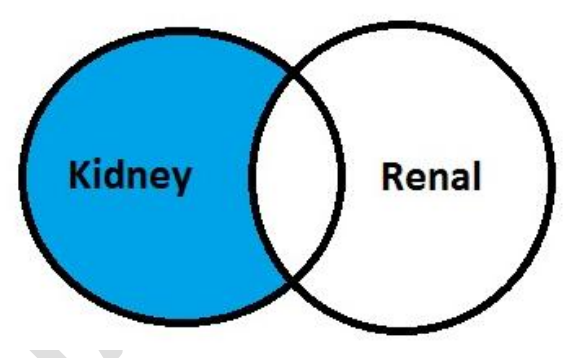

NOT

(To narrow search-both terms)

(To expend search i.e. either term)

(Eliminate-Only one term)

\begin{tabular}{|c|l|}
\hline Search strategy & Explanation \\
\hline $\begin{array}{c}\text { 1. (kidney or renal).ti,ab.. } \\
\text { neoplas*).ti,ab. }\end{array}$ & $\begin{array}{l}\text { This will retrieve records with the word "kidney" or "renal" in the title } \\
\text { or abstract. }\end{array}$ \\
\hline 3. 1 and 2 & $\begin{array}{l}\text { This will retrieve records that have used the word related to cancer and } \\
\text { the synonyms and variations of root words, such as carcinoma(s), } \\
\text { malignant, malignancy, malignancies, tumor, tumour, neoplasm(s), } \\
\text { neoplastic, etc. }\end{array}$ \\
\hline 4. exp Kidney Neoplasms/ & $\begin{array}{l}\text { This search string combines terms related to kidney and cancer and will } \\
\text { identify all records mentioning both terms in the titles or abstracts. }\end{array}$ \\
\hline $5 . \quad 3$ or 4 & $\begin{array}{l}\text { This will identify records that tagged with the Medical Subject Heading } \\
\text { (MeSH) term "kidney neoplasms" (exploded) }\end{array}$ \\
\hline $6 . \quad$ exp animals/ not humans/ & $\begin{array}{l}\text { This will retrieve records related to kidney cancer using text words as } \\
\text { well as the MeSH term. }\end{array}$ \\
\hline 7. 5 not 6 & $\begin{array}{l}\text { This will retrieve records tagged with the MeSH term "animals"; } \\
\text { records that tagged with both animals and humans MeSH terms will } \\
\text { not be captured. }\end{array}$ \\
\hline
\end{tabular}

Figure 2: Example of search strategy

Page 18 of $\mathbf{3 0}$ 


\begin{tabular}{|c|c|c|}
\hline & Systematic review & Traditional review \\
\hline Review Question & $\begin{array}{l}\text { Focused, well-defined clinical question formulated } \\
\text { with PICO framework }\end{array}$ & Question is usually broad and not well defined. \\
\hline Protocol & a-priori protocol is developed and published & No protocol \\
\hline Methods & $\begin{array}{l}\text { Usually very well-defined and explicitly stated with } \\
\text { study inclusion and exclusion criteria. }\end{array}$ & Usually not well-defined. \\
\hline Literature search & $\begin{array}{l}\text { A good systematic review includes a well-defined } \\
\text { comprehensive search, without language or other } \\
\text { restrictions. }\end{array}$ & $\begin{array}{l}\text { Search strategy is usually not stated and the review is } \\
\text { confined to well-known articles often supporting the } \\
\text { authors' views. }\end{array}$ \\
\hline Critical appraisal & $\begin{array}{l}\text { Internal validity of the individual studies included in a } \\
\text { systematic review is vetted by various tools such as } \\
\text { Cochrane risk of bias assessment tool. }\end{array}$ & Critical appraisal is usually not performed \\
\hline Synthesis & $\begin{array}{l}\text { Qualitative (sometimes quantitative with meta- } \\
\text { analysis) - May answer a clinical question which may } \\
\text { not be answerable by individual studies. }\end{array}$ & Usually qualitative summary \\
\hline Findings/Conclusion & Findings are reproducible. & $\begin{array}{l}\text { Findings are not reproducible. Author's personal belief } \\
\text { may influence the overall conclusion of a traditional } \\
\text { review. }\end{array}$ \\
\hline
\end{tabular}

Table 1: Differences between a systematic review and traditional review 


\begin{tabular}{|c|c|}
\hline $\begin{array}{l}\text { Data extraction } \\
\text { form field }\end{array}$ & Information to consider in data extraction \\
\hline $\begin{array}{c}\text { Reviewer } \\
\text { Identification }\end{array}$ & Review author ID; date \\
\hline Study Identification & $\begin{array}{l}\text { Study ID; Report ID; Citation; Author Contact details; } \\
\text { Publication year; Country; Source of data }\end{array}$ \\
\hline Methods & Study design; Setting; Enrolment period; Number of centres \\
\hline $\begin{array}{c}\text { Participant } \\
\text { Characteristics }\end{array}$ & $\begin{array}{l}\text { Total number; Age; Gender; Co-morbidity; Ethnicity; Number } \\
\text { lost to follow-up }\end{array}$ \\
\hline $\begin{array}{c}\text { Disease } \\
\text { Characteristics }\end{array}$ & $\begin{array}{l}\text { Staging (e.g. TNM); Severity (e.g. IPSS score), Biological } \\
\text { behaviour (e.g. Gleason score); Surgical complexity(e.g. } \\
\text { R.E.N.A.L. score); Method of diagnosis }\end{array}$ \\
\hline Interventions* & $\begin{array}{l}\text { Surgical technique; Surgeon experience/volume; Drug dose, } \\
\text { route of delivery and length. }\end{array}$ \\
\hline $\begin{array}{l}\text { Diagnostic test } \\
\text { Characteristics }^{* *}\end{array}$ & $\begin{array}{l}\text { Description of the reference standard, index test, } \\
\text { comparator, manufacturer; interpreter of diagnostic test. }\end{array}$ \\
\hline $\begin{array}{l}\text { Prognostic factor } \\
\text { characteristics } * * *\end{array}$ & Dose, level, duration of exposure; Method of measurement; \\
\hline Outcome & $\begin{array}{l}\text { Outcome definition (incl. unit of measurement, scale, } \\
\text { assessor, time point of measurement) }\end{array}$ \\
\hline $\begin{array}{l}\text { Results to include in } \\
\text { a meta-analysis }\end{array}$ & $\begin{array}{l}\text { Dichotomous outcomes: number of events / number of } \\
\text { participants } \\
\text { Continuous outcomes: mean value and SD in each } \\
\text { intervention group } \\
\text { Time-to-event outcomes: HR (with 95\% CI) } \\
\text { Diagnostic test Performance outcomes: TP, FP, TN, FN }\end{array}$ \\
\hline Risk of Bias & $\begin{array}{l}\text { Cochrane RoB tool for RCTs or other tools such as QUIPS and } \\
\text { QUADAS-2 }\end{array}$ \\
\hline Other & Review author comments \\
\hline $\begin{array}{l}* \text { For Comparative Eff } \\
* * \text { For Diagnostic Test } \\
* * * \text { For Prognostic Fa }\end{array}$ & $\begin{array}{l}\text { ectiveness of Interventions Systematic Reviews } \\
\text { Accuracy Systematic Reviews } \\
\text { tor Systematic Reviews }\end{array}$ \\
\hline
\end{tabular}

Table 2- Information to consider in data extraction form. 


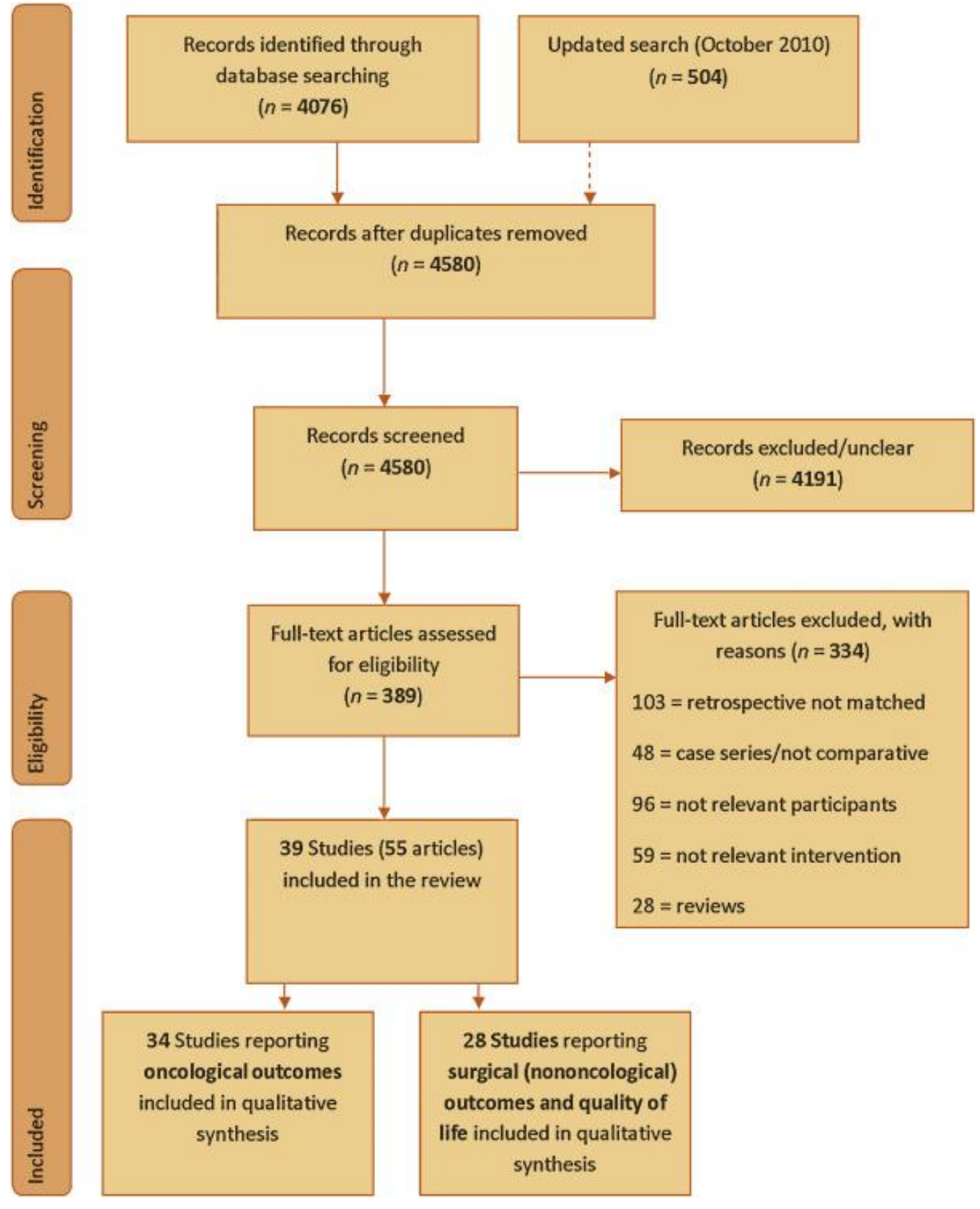

Figure 311: Example PRISMA flowchart [42]. 


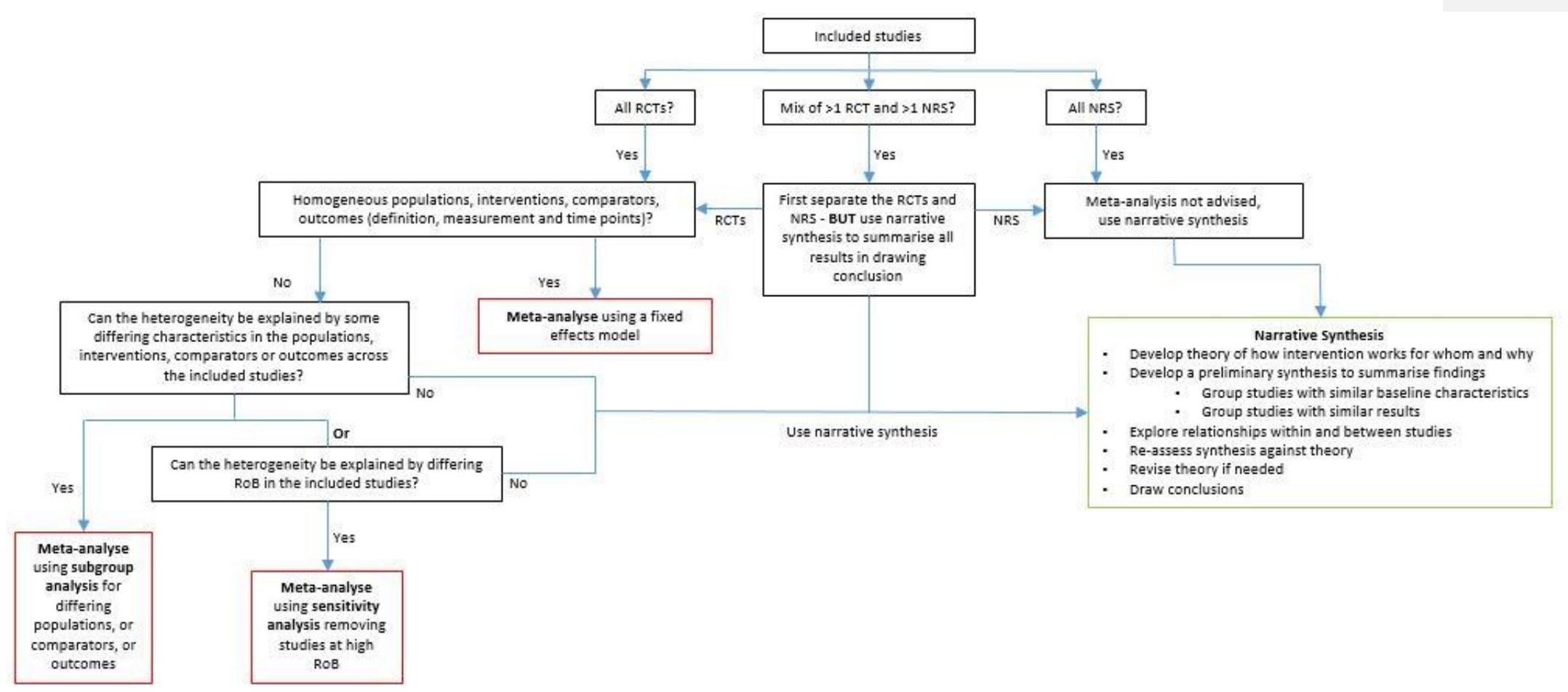

Figure 42: A decision flow diagram when to meta-analyse data or to use narrative synthesis. 


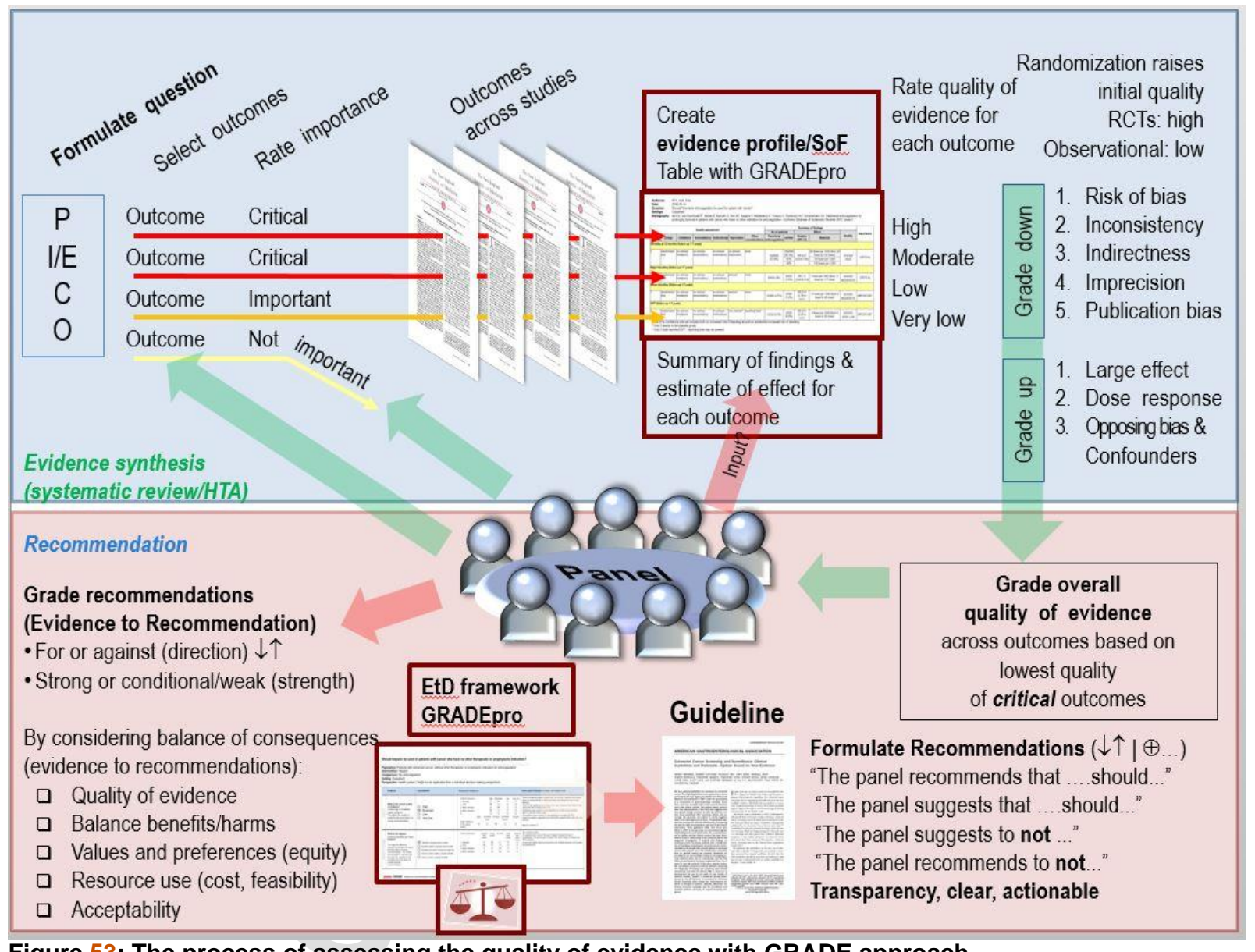

Figure $\underline{5} 3$ : The process of assessing the quality of evidence with GRADE approach 


\begin{tabular}{|c|c|}
\hline $\begin{array}{l}\text { Published systematic reviews conducted under the auspices of the EAU Guidelines } \\
\text { Office }\end{array}$ & Guideline recommendation(s) underpinned by this SR \\
\hline $\begin{array}{l}\text { Viktor Soukup, Otakar Capoun, Daniel Cohen, Virginia Hernandez, Marek Babjuk, et al.. } \\
\text { Prognostic Performance and Reproducibility of the } 1973 \text { and 2004/2016 World Health } \\
\text { Organization Grading Classification Systems in Non-muscle-invasive Bladder Cancer: A } \\
\text { European Association of Urology Non-muscle Invasive Bladder Cancer Guidelines Panel } \\
\text { Systematic Review. Eur Urol 2017, in press }\end{array}$ & To appear in the 2018 NMIBC Guidelines \\
\hline $\begin{array}{l}\text { Hernández V, Espinos EL, Dunn J, MacLennan S, Lam T, Yuan Y, et al. .Onco } \\
\text { functional outcomes of sexual function-preserving cystectomy compared w } \\
\text { cystectomy in men: A systematic review. Urol Oncol. } 2017 \text { May 8. pii: S1078 } \\
\text { doi: 10.1016/j.urolonc.2017.04.013. [Epub ahead of print] }\end{array}$ & $\begin{array}{l}\text { The majority of patients motivated to preserve their sexual function will } \\
\text { benefit from sexual-preserving techniques. LE } 2 \\
\text { None of the sexual-preserving techniques } \\
\text { (prostate/capsule/seminal/nerve sparing) have shown to be } \\
\text { superior and no particular technique can be recommended. LE } 2 \\
\text { Offer sexual-preserving techniques to men motivated to preserve their } \\
\text { sexual function since the majority will benefit. LE } 2 \text { GR B } \\
\text { Select patients based on: } \\
\text { - Organ-confined disease; } \\
\text { - Absence of any kind of tumour at the level of the prostate, prostatic } \\
\text { urethra or bladder neck. } \\
\text { LE 2. GR A } \\
\text { Do not offer sexual-preserving cystectomy as standard therapy for } \\
\text { MIBC. GR C } \\
\text { Guideline year: } 2016\end{array}$ \\
\hline $\begin{array}{l}\text { Seisen T, Peyronnet B, Dominguez-Escrig JL, Bruins HM, Yuan CY, Babjuk M, et al.. Oncologic } \\
\text { Outcomes of Kidney-sparing Surgery Versus Radical Nephroureterectomy for Upper Tract } \\
\text { Urothelial Carcinoma: A Systematic Review by the EAU Non-muscle Invasive Bladder Cancer }\end{array}$ & $\begin{array}{l}\text { EAU guideline on Upper Urinary Tract Urothelial Carcinoma 2017, } \\
\text { chapter 7.1.1.4: } \\
\text { Offer kidney-sparing management as primary treatment option to }\end{array}$ \\
\hline
\end{tabular}

Page $\mathbf{2 4}$ of $\mathbf{3 0}$ 
Guidelines Panel. Eur Urol. 2016 Dec;70(6):1052-1068. doi: 10.1016/j.eururo.2016.07.014. Epub 2016 Jul 28.

Bruins HM, Veskimae E, Hernandez V, Imamura M, Neuberger MM, Dahm P, et al.. The impact of the extent of lymphadenectomy on oncologic outcomes in patients undergoing radical cystectomy for bladder cancer: a systematic review. Eur Urol. 2014 Dec;66(6):1065-77. doi:

10.1016/j.eururo.2014.05.031. Epub 2014 Jul 26.

Hoen L', Ecclestone H, Blok BF, Karsenty G, Phé $\mathrm{V}$, Bossier R, et al. Long-term effectiveness and complication rates of bladder augmentation in patients with neurogenic bladder dysfunction: A systematic review. Neurourol Urodyn. 2017 Feb 7. doi: 10.1002/nau.23205. [Epub ahead of print]

Phé V, Boissier R, Blok BF, Del Popolo G, Musco S, Castro-Diaz D, et al.. Continent catheterizable tubes/stomas in adult neuro-urological patients: A systematic review.

Neurourol Urodyn. 2017 Jan 31. doi: 10.1002/nau. 23213. [Epub ahead of print]

Gross T, Schneider MP, Bachmann LM, Blok BF, Groen J, Hoen LA, et al.. Transcutaneous

Electrical Nerve Stimulation for Treating Neurogenic Lower Urinary Tract Dysfunction: A

Systematic Review. Eur Urol. 2016 Jun;69(6):1102-11. doi: 10.1016/j.eururo.2016.01.010. Epub $2016 \operatorname{Jan} 29$. patients with low-risk tumour and two functional kidneys

EAU guideline Muscle-Invasive and Metastatic Bladder Cancer 2017, chapter 7.4.7:

Perform a lymph node dissection as an integral part of cystectomy.

To appear in the 2018 NMIBC Guidelines

To appear in the 2018 NMIBC Guidelines

No Guideline recommendation but cited (Nbr 138)

\subsubsection{Neuro-urological rehabilitation}

\subsubsection{Bladder rehabilitation including electrical stimulation}

The term bladder rehabilitation summarises treatment options that aim to re-establish bladder function in patients with neuro-urological

symptoms. Strong contraction of the urethral sphincter and/or pelvic floor, as well as anal dilatation, manipulation of the genital region, and physical activity inhibit micturition in a reflex manner $[119,136]$. The first mechanism is affected by activation of efferent nerve fibres, and the latter ones are produced by activation of afferent fibres [98]

Electrical stimulation of the pudendal nerve afferents strongly inhibits the micturition reflex and detrusor contraction [137]. This stimulation might then support the restoration of the balance between excitatory and inhibitory inputs at the spinal or supraspinal level $[119,138]$.

Evidence for bladder rehabilitation using electrical stimulation in

neurological patients is mainly based on small non-comparative studies with high risk of bias.

Peripheral temporary electrostimulation: Tibial nerve stimulation and transcutaneous electrical nerve stimulation might be effective and safe 


\begin{tabular}{|c|c|}
\hline & $\begin{array}{l}\text { for treating neurogenic lower urinary tract dysfunction, but more } \\
\text { reliable evidence from well-designed RCTs is required to reach definitive } \\
\text { conclusions }[138,139] \text {. }\end{array}$ \\
\hline $\begin{array}{l}\text { Schneider MP, Gross T, Bachmann LM, Blok BF, Castro-Diaz D, Del Popolo G, et al.. Tibial Nerve } \\
\text { Stimulation for Treating Neurogenic Lower Urinary Tract Dysfunction: A Systematic Review. } \\
\text { Eur Urol. } 2015 \text { Nov;68(5):859-67. doi: 10.1016/j.eururo.2015.07.001. Epub } 2015 \text { Jul 18. }\end{array}$ & $\begin{array}{l}\text { No Guideline recommendation but cited (Nbr 139) } \\
\text { 3.4.2.2. Neuro-urological rehabilitation } \\
\text { 3.4.2.2.1. Bladder rehabilitation including electrical stimulation } \\
\text { The term bladder rehabilitation summarises treatment options that aim } \\
\text { to re-establish bladder function in patients with neuro-urological } \\
\text { symptoms. Strong contraction of the urethral sphincter and/or pelvic } \\
\text { floor, as well as anal dilatation, manipulation of the genital region, and } \\
\text { physical activity inhibit micturition in a reflex manner [119,136]. The } \\
\text { first mechanism is affected by activation of efferent nerve fibres, and } \\
\text { the latter ones are produced by activation of afferent fibres [98]. } \\
\text { Electrical stimulation of the pudendal nerve afferents strongly inhibits } \\
\text { the micturition reflex and detrusor contraction [137]. This stimulation } \\
\text { might then support the restoration of the balance between excitatory } \\
\text { and inhibitory inputs at the spinal or supraspinal level [119,138]. } \\
\text { Evidence for bladder rehabilitation using electrical stimulation in } \\
\text { neurological patients is mainly based on small non-comparative studies } \\
\text { with high risk of bias. } \\
\text { Peripheral temporary electrostimulation: Tibial nerve stimulation and } \\
\text { transcutaneous electrical nerve stimulation might be effective and safe } \\
\text { for treating neurogenic lower urinary tract dysfunction, but more } \\
\text { reliable evidence from well-designed RCTs is required to reach definitive } \\
\text { conclusions [138,139]. }\end{array}$ \\
\hline $\begin{array}{l}\text { Sujenthiran A, Elshout PJ, Veskimäe E, MacLennan S, Yan Y, Serafetinidis E, et al.. I } \\
\text { operative management the best first-line option for high-grade renal trauma? A sy } \\
\text { review. European Urology Focus } 2017 \text { May 29; doi:10.1016/j.euf.2017.04.011 }\end{array}$ & $\begin{array}{l}\text { Urogenital Trauma Guidelines 2017; Ch 4.1.3.1.1. Blunt renal injuries; LE } \\
\text { 3, GR B }\end{array}$ \\
\hline $\begin{array}{l}\text { Elshout PJ, Veskimae E, MacLennan S, Yuan Y, Lumen N, Gonsalves M, et al.. } \\
\text { Outcomes of Early Endoscopic Realignment Versus Suprapubic Cystostomy and } \\
\text { Delayed Urethroplasty for Pelvic Fracture-related Posterior Urethral Injuries: A } \\
\text { Systematic Review. European Urology Focus } 2017 \text { Mar 6; doi: }\end{array}$ & $\begin{array}{l}\text { Urogenital Trauma Guidelines 2017; Ch 4.4.1.2.2. Posterior urethral } \\
\text { injuries (in males). LE 2a, GR B }\end{array}$ \\
\hline
\end{tabular}




\subsection{6/j.euf.2017.03.001}

Veskimäe E, Nezuillet Y, Rouanne M, MacLennan S, Lam T, Yuan Y, et al.. What are the oncological and functional outcomes of pelvic organ-preserving cystectomy compared with standard radical cystectomy in women with bladder cancer and a neobladder? Systematic review. BJU Int. 2017 Feb 20. doi: 10.1111/bju.13819

Ruhayel Y, Tepeler A, Dabestani S, MacLennan S, Petřík A, Sarica K, et al.. Tract Sizes in Miniaturized Percutaneous Nephrolithotomy: A Systematic Review from the European Association of Urology Urolithiasis Guidelines Panel. Eur Urol. 2017 Aug;72(2):220-235. doi: 10.1016/j.eururo.2017.01.046. Epub 2017 Feb 23. PubMed PMID: 28237786.

Drake T, Grivas N, Dabestani S, Knoll T, Lam T, Maclennan S, et al. What are the Benefits and Harms of Ureteroscopy Compared with Shock-wave Lithotripsy in the Treatment of Upper Ureteral Stones? A Systematic Review. Eur Urol. 2017 Apr 26. pii:S0302-2838(17)30324-X. do 10.1016/j.eururo.2017.04.016. [Epub ahead of print] Review. PubMed PMID: 28456350. Preminger GM, Tiselius HG, Assimos DG, Alken P, Buck AC, Gallucci M, et al.; American Urological Association Education and Research, Inc; European Association of Urology. 2007 Guideline for the management of ureteral calculi. Eur Urol. 2007

Dec;52(6):1610-31. PubMed PMID: 18074433.

Silay MS, Undre S, Nambiar AK, Dogan HS, Kocvara R, et al.. Role of antibiotic prophylaxis in antenatal hydronephrosis: A systematic

review from the European Association of Urology/European Society for Paediatric

Urology Guidelines Panel. J Pediatr Urol. 2017 Jun;13(3):306-315. doi:

10.1016/j.jpurol.2017.02.023. Epub 2017 Mar 19.

\section{Covich of the}

Malde S, Nambiar AK, Umbach R, Lam TB, Bach T, et al. Systematic Review of the Performance of Noninvasive Tests in Diagnosing Bladder Outlet Obstruction in Men with

Lower Urinary Tract Symptoms. Eur Urol. 2017 Mar;71(3):391-402 doi:

10.1016/j. ururo. 2016.09.026. Epub 2016 Sep 2 -

Marconi L, Dabestani S, Lam TB, Hofmann F, Stewart F, Norrie J, et al. Systematic Review and

Meta-analysis of Diagnostic Accuracy of Percutaneous Renal Tumour Biopsy. Eur Urol. 2016

Apr;69(4):660-73. doi: 10.1016/j.eururo.2015.07.072. Epub 2015 Aug 29.
MIBC 2017; Ch 7.4.3.2. Pelvic organ preservation techniques in women: oncological and functional outcomes; LE 3, GR C; new chapter based on the review

\section{Guideline on Urolithiasis 2016 onwards}

Statement on tract sizes for percutaneous nephrolithotomy .

Guideline on Urolithiasis 2016 onwards

Recommendations on inventional treatment for upper ureteral calculi

Guideline on Urolithiasis 2008 onwards until update in 2016

Recommendations and statements on management of ureteral calculi

In children diagnosed with antenatal hydronephrosis, a systematic

review could not establish any benefits or harms related to continuous antibiotic prophylaxis. (1b)

In children diagnosed with antenatal hydronephrosis, non-circumcised infants (LE: 1a), children diagnosed with high-grade hydronephrosis (LE: 2) and hydroureteronephrosis (LE: 1 b) were shown to be at higher risk of developing UTI.

None of the non-invasive tests in diagnosing bladder outlet obstruction in men with LUTS can currently be recommended as an alternative to pressure-flow studies. Grade B

\section{Use a coaxial technique when performing a renal tumour biopsy.}

strong $\uparrow \uparrow$

2. Do not perform a renal tumour biopsy of cystic renal masses. weak $\downarrow$ 3. Perform a percutaneous biopsy in select patients who are considered for active surveillance, weak $\uparrow$ (This recommendation was indirectly 
't Hoen LA, Groen J, Scheepe JR, Reuvers S, Diaz DC, Fernández BP, et al. A Quality Assessment of Patient-Reported Outcome Measures for Sexual Function in Neurologic Patients Using the Consensus-based Standards for the Selection of Health Measurement Instruments Checklist: A Systematic Review. Eur Urol Focus. 2016 Jun 23. pii: S2405-4569(16)30069-4. doi:

10.1016/j.euf.2016.06.009. [Epub ahead of print]

Moldovan PC, Van den Broeck T, Sylvester R, Marconi L, Bellmunt J, van den Bergh RCN, et al.

What Is the Negative Predictive Value of Multiparametric Magnetic Resonance Imaging in

Excluding Prostate Cancer at Biopsy? A Systematic Review and Meta-analysis from the

European Association of Urology Prostate Cancer Guidelines Panel. Eur Urol (2017),

http://dx.doi.org/10.1016/j.eururo.2017.02.026

Sakalis $V^{1}$, Karavitakis M, Bedretdinova D, Bach T, Bosch JLHR, Gacci M, et al. Medical

Treatment of Nocturia in Men with Lower Urinary Tract Symptoms: Systematic Review by the

European Association of Urology Guidelines Panel for Male Lower Urinary Tract Symptoms. Eur

Urol. 2017 Jun 27. pii: S0302-2838(17)30505-5. doi: 10.1016/j.eururo.2017.06.010. [Epub

ahead of print]

Fossati N, Willemse PM, Van den Broeck T, van den Bergh RCN, Yuan CY, Briers E, et al. The Benefits and Harms of Different Extents of Lymph Node Dissection During Radical

Prostatectomy for Prostate Cancer: A Systematic Review. Eur Urol. 2017 Jul;72(1):84-109. doi:

Prostatectomy for Prostate Cancer: A Systematic Revi

derived from the Systematic Review)

o appear in the 2018 Guidelines.

To appear in the 2018 Guidelines

To appear in the 2018 Guidelines

To appear in the 2018 Guidelines

Table A: Guideline recommendation(s) underpinned by the selected SRs conducted under the auspices of the EAU Guidelines

Office. 


\section{References:}

[1] Cochrane AL. Effectiveness and efficiency : random reflections on health services. [S.I.]: The Nuffield Provincial Hospitals Trust; 1972.

[2] Sylvester RJ, Oosterlinck W, Holmang S, Sydes MR, Birtle A, Gudjonsson S, et al. Systematic Review and Individual Patient Data Meta-analysis of Randomized Trials Comparing a Single Immediate Instillation of Chemotherapy After Transurethral Resection with Transurethral Resection Alone in Patients with Stage pTa-pT1 Urothelial Carcinoma of the Bladder: Which Patients Benefit from the Instillation? Eur Urol. 2016;69:231-44.

[3] Marconi L, Dabestani S, Lam TB, Hofmann F, Stewart F, Norrie J, et al. Systematic Review and Metaanalysis of Diagnostic Accuracy of Percutaneous Renal Tumour Biopsy. Eur Urol. 2016;69:660-73.

[4] Dabestani S, Marconi L, Hofmann F, Stewart F, Lam TB, Canfield SE, et al. Local treatments for metastases of renal cell carcinoma: a systematic review. Lancet Oncol. 2014;15:e549-61.

[5] EAU Guidelines. Edn. presented at the EAU Annual Congress London 2017.

[6] Altman DG, Schulz KF, Moher D, Egger M, Davidoff F, Elbourne D, et al. The revised CONSORT statement for reporting randomized trials: explanation and elaboration. Ann Intern Med. 2001;134:66394.

[7] Higgins J, Green S. Cochrane handbook for systematic reviews of interventions. Version 5.1.0 Oxford: The Cochrane Collaboration; 2011.

[8] Glass; G, Smith M. Meta-analysis of research on the relationship of class-size and achievement. Educational Evaluation and Policy Analysis. 1979;1:2-16.

[9] Blettner M, Sauerbrei W, Schlehofer B, Scheuchenpflug T, Friedenreich C. Traditional reviews, metaanalyses and pooled analyses in epidemiology. Int J Epidemiol. 1999;28:1-9.

[10] Mulrow CD. The medical review article: state of the science. Ann Intern Med. 1987;106:485-8.

[11] Huang X LJ, Demner-Fushman D. Evaluation of PICO as a knowledge representation for clinical questions. AMIA Annu Symp Proc. 2006:359-63.

[12] PROSPERO. International prospective register of systematic reviews. Available from: https://www.crd.york.ac.uk/prospero/about.php?about=citerecord\#index.php. Accessed on 5th March 2017.

[13] Higgins JP, Lasserson T, Chandler J, Tovey D, R C. Expectations of Cochrane Intervention Reviews (MECIR) Standards for the conduct and reporting of new Cochrane Intervention Reviews, reporting of protocols and the planning, conduct and reporting of updates. Available from: http://methods.cochrane.org/mecir Accessed on 5th March 2017.

[14] Moher D, Liberati A, Tetzlaff J, Altman DG, Group P. Preferred reporting items for systematic reviews and meta-analyses: the PRISMA statement. J Clin Epidemiol. 2009;62:1006-12.

[15] PRISMA. Preferred Reporting Items for Systematic Reviews and Meta-Analyses (PRISMA). Available from http://www.prisma-statement.org/. Accessed on 5th March 2017.

[16] Buscemi N, Harding L, Vandermeer B, Tjosvold L, Klassen TP. Single data extraction generated more errors than double data extraction in systematic reviews. Journal of Clinical Epidemiology. 2006;59:697703.

[17] MacLennan S, Williamson PR, Bekema H, Campbell M, Ramsay C, N'Dow J, et al. A core outcome set for localised prostate cancer effectiveness trials. BJU Int. 2017.

[18] Higgins JP, Altman DG, Gotzsche PC, Juni P, Moher D, Oxman AD, et al. The Cochrane Collaboration's tool for assessing risk of bias in randomised trials. BMJ. 2011;343:d5928.

[19] Review Manager (RevMan) [Computer program]. Version 5.3. Copenhagen: The Nordic Cochrane Centre, The Cochrane Collaboration, 2014.

[20] Higgins JPT, Sterne JAC, Savović J, Page MJ, Hróbjartsson A, Boutron I, et al. A revised tool for assessing risk of bias in randomized trials. In: Chandler J, McKenzie J, Boutron I, Welch V (editors). Cochrane Methods. Cochrane Database of Systematic Reviews. 2016;Issue 10 (Suppl 1).

[21] Sterne JA, Hernan MA, Reeves BC, Savovic J, Berkman ND, Viswanathan M, et al. ROBINS-I: a tool for assessing risk of bias in non-randomised studies of interventions. BMJ. 2016;355:i4919. 
[22] Whiting PF, Rutjes AW, Westwood ME, Mallett S, Deeks JJ, Reitsma JB, et al. QUADAS-2: a revised tool for the quality assessment of diagnostic accuracy studies. Ann Intern Med. 2011;155:529-36.

[23] Hayden JA, van der Windt DA, Cartwright JL, Cote P, Bombardier C. Assessing bias in studies of prognostic factors. Ann Intern Med. 2013;158:280-6.

[24] Egger M, Smith GD, Phillips AN. Meta-analysis: principles and procedures. BMJ. 1997;315:1533-7.

[25] Mulrow CD. Rationale for systematic reviews. BMJ. 1994;309:597-9.

[26] Higgins JPT. Commentary: Heterogeneity in meta-analysis should be expected and appropriately quantified. Int J Epidemiol. 2008;37:1158-60.

[27] Higgins JPT, Thompson SG, Deeks JJ, Altman DG. Measuring inconsistency in meta-analyses. Brit Med J. 2003;327:557-60.

[28] Yusuf S, Wittes J, Probstfield J, Tyroler HA. Analysis and Interpretation of Treatment Effects in Subgroups of Patients in Randomized Clinical-Trials. Jama-J Am Med Assoc. 1991;266:93-8.

[29] Oxman AD, Guyatt GH. A consumer's guide to subgroup analyses. Ann Intern Med. 1992;116:78-84.

[30] Harden A, J T. Methodological Issues in Combining Diverse Study Types in Systematic Reviews. International Journal of Social Research Methodology. 2005;8:257-71.

[31] Thornton A, Lee P. Publication bias in meta-analysis: its causes and consequences. Journal of Clinical Epidemiology. 2000;53:207-16.

[32] Mays N, Pope C, Popay J. Systematically reviewing qualitative and quantitative evidence to inform management and policy-making in the health field. J Health Serv Res Policy. 2005;10 Suppl 1:6-20.

[33] Popay J, Roberts H, Sowden A, Petticrew M, Arai L, Rodgers M, et al. Guidance on the conduct of narrative synthesis in systematic reviews. ESRC Research Methods Programme2006.

[34] Guyatt G, Oxman AD, Akl EA, Kunz R, Vist G, Brozek J, et al. GRADE guidelines: 1. IntroductionGRADE evidence profiles and summary of findings tables. J Clin Epidemiol. 2011;64:383-94.

[35] Canfield SE, Dahm P. Rating the quality of evidence and the strength of recommendations using GRADE. World J Urol. 2011;29:311-7.

[36] Balshem H, Helfand M, Schunemann HJ, Oxman AD, Kunz R, Brozek J, et al. GRADE guidelines: 3. Rating the quality of evidence. J Clin Epidemiol. 2011;64:401-6.

[37] Guyatt GH, Thorlund K, Oxman AD, Walter SD, Patrick D, Furukawa TA, et al. GRADE guidelines: 13. Preparing Summary of Findings tables and evidence profiles-continuous outcomes. Journal of Clinical Epidemiology. 2013;66:173-83.

[38] Plot Digitizer. Available from http://plotdigitizer.sourceforge.net/. Accessed on 5th March 2017.

[39] Software for systematic reviewing. Available from http://hlwiki.slais.ubc.ca/index.php/Software for systematic reviewing. Accessed on 5th March 2017. [40] Brown T. It's time for alltrials registered and reported. Cochrane Database Syst Rev. 2013:ED000057.

[41] Elliott J, Sim I, Thomas J, Owens N, Dooley G, Riis J, et al. \#CochraneTech: technology and the future of systematic reviews [editorial]. Cochrane Database of Systematic Reviews2014.

[42] MacLennan S, Imamura M, Lapitan MC, Omar MI, Lam TB, Hilvano-Cabungcal AM, et al. Systematic review of perioperative and quality-of-life outcomes following surgical management of localised renal cancer. Eur Urol. 2012;62:1097-117.

\section{Acknowledgement:}

Figure 53 was created by the GRADE Working Group. We are grateful to Professor Holger Schünemann, from McMaster University, for allowing us to use this figure. 
$9^{\text {th }}$ August 2017

Ms. No: EURUROL-D-17-00952

Title: Conducting systematic reviews for underpinning clinical practice guidelines: Experience of the European Association of Urology

Dear Professor Catto,

We are grateful to the referees for their extremely helpful comments and suggestions. We are now re-submitting the manuscript after incorporating necessary changes.

Please let us know if there are still any required changes.

With profound regards,

Muhammad Imran Omar

(On behalf

of author

team) 


\begin{tabular}{|c|c|}
\hline Reviewer's comments & Response from the author team \\
\hline $\begin{array}{l}\text { Reviewer \#1: Knoll and colleagues from the EAU and EAU } \\
\text { Guidelines Office reported in a didactical manner the key steps to } \\
\text { follow to perform a good SR with MA. } \\
\text { The following points should be considered. }\end{array}$ & $\begin{array}{l}\text { 1. We have modified the title. The title now reads as: } \\
\text { "Key steps in conducting systematic reviews for } \\
\text { underpinning clinical practice guidelines: Methodology of } \\
\text { the European Association of Urology" }\end{array}$ \\
\hline $\begin{array}{l}\text { Major comments: } \\
\text { 1) The title is not appropriate. What is reported here is not the } \\
\text { "experience" of the EAU, but mainly the key steps to follow to } \\
\text { perform a good SR with MA. } \\
\text { 2) Similarly, no evidence is here provided that SRs with MAs have } \\
\text { underpinned clinical practice guidelines. Solely, the key steps to } \\
\text { perform a good SR with MA are reported. }\end{array}$ & $\begin{array}{l}\text { 2. We have now added following information: } \\
\text { "The Guidelines Office has completed } 21 \text { systematic reviews and } \\
32 \text { reviews are ongoing. These high quality systematic reviews } \\
\text { are used for making guideline recommendations (Reference: } \\
\text { EAU Guidelines. Edn. presented at the EAU Annual Congress } \\
\text { London } 2017 . \text { ISBN 978-90-79754-91-5.)." } \\
\text { Table A (online supplement) summarizes Guideline } \\
\text { recommendation(s) underpinned by the selected SRs conducted } \\
\text { under the auspices of the EAU Guidelines Office. } \\
\text { Note: There are a large number of systematic reviews published } \\
\text { under the auspices of the EAU Guidelines Office. These are } \\
\text { either already used to underpin Clinical Practice Guidelines, or } \\
\text { will be used for the next update of the EAU Guidelines. The } \\
\text { Table is attached with this response letter (pages } 7 \text { onwards) as } \\
\text { well as the manuscript Table A. The table might be too detailed } \\
\text { for the print version, but will be helpful to the reader if added as } \\
\text { an online supplement. }\end{array}$ \\
\hline $\begin{array}{l}\text { Reviewer \#2: Systematic reviews (SR) and meta-analysis (MA) are } \\
\text { essential in providing level } 1 \text { evidence for clinical practice. } \\
\text { National and international (including EAU) guidelines are partly } \\
\text { developed based on SR and MA. Therefore, it is vital that SR and } \\
\text { MA are conducted appropriately at a standardised level. The }\end{array}$ & \\
\hline
\end{tabular}


authors aimed to provide step-wise guidance on conducting $\mathrm{SR} /$ Mas including forming the research question, literature review, data extraction/interpretation, and conclusions based on analyses.

Please include line numbers for comments/corrections/resubmission purposes.

1) What is a systematic review section- please provide a reference for your definition

2) Table 1 summarising the key differences between SR and Traditional review is good

3) Formulating research section- please provide a reference for PICO so readers can understand more about this framework. Although RCT is not the topic of this article but it has been mentioned throughout, maybe include a sentence and a reference on RCT protocols such as CONSORT??

4) There's a lot of text in the article. Maybe include a flow diagram to summarise the key steps (your sub-headings) in conducting a SR ie. Formulating a question- literature searchabstract/full text screening- data extraction- RoB assessment- ....

There are a few articles in the literature already on conducting SR/MA. EU have published guidelines on statistics for EU, and since EAU guidelines are partly based on SR/MA, it is not unreasonable to have EU guidance on conducting SR/MA. This review summarises the key elements of SR/MA and would provide a framework for researchers conducting SR/MA.
1. We have now added the following reference:

Higgins J, Green S. Cochrane handbook for systematic reviews of interventions. Version 5.1.0 Oxford: The Cochrane Collaboration; 2011.

2. Thank you. No changes required

3. We have now added following reference for PICO:

Huang X1, Lin J, Demner-Fushman D. Evaluation of PICO as a knowledge representation for clinical questions. AMIA Annu Symp Proc. 2006:359-63.

We have added the following:

\section{What is a randomized controlled trial?}

A randomized controlled trial (RCT) is a type of study in which participants are randomly assigned to two or more groups in order to assess interventions. A well designed RCT is adequately powered and follows the principles and recommendations of the CONSORT statement. 


\begin{tabular}{|c|c|}
\hline & $\begin{array}{l}\text { Reference: Altman DG1, Schulz KF, Moher D, Egger M, Davidoff F, } \\
\text { Elbourne D, Gøtzsche PC, Lang T; CONSORT GROUP } \\
\text { (Consolidated Standards of Reporting Trials). The revised } \\
\text { CONSORT statement for reporting randomized trials: explanation } \\
\text { and elaboration. Ann Intern Med. } 2001 \text { Apr 17;134(8):663-94. } \\
\text { 4. We have now added a flow diagram, summarizing the key steps of } \\
\text { conducting systematic review. Also copied on the page } 5 \text { of this } \\
\text { response letter. }\end{array}$ \\
\hline $\begin{array}{l}\text { Reviewer \#3: I like this paper a lot and believe it will attract a lot } \\
\text { of interest from the readership, especially residents in the early } \\
\text { phases of research and academic endeavour. } \\
\text { Some minor edits/thoughts: } \\
\text { Key messages: third bullet point requires - An extensive... } \\
\text { General comments in text: abbreviations used interchangeably } \\
\text { e.g. MA and meta-analysis. Once abbreviation established in text, } \\
\text { please stick to abbreviated form as supposed to switching } \\
\text { between them. } \\
\text { Explanation of how to log a study with Prospero or what Propsero } \\
\text { is e.g. University of York database.. Perhaps not as well } \\
\text { identifiable as Cochrane library. } \\
\text { Authors describe using the Boolean operators correctly in the } \\
\text { search bar, but an example of this would be useful to general }\end{array}$ & $\begin{array}{l}\text { 1. Amended third key message as suggested } \\
\text { 2. Made necessary edits about abbreviations. } \\
\text { 3. We have added the following: } \\
\text { PROSPERO is a database maintained by the University of York. } \\
\text { PROSPERO provides a free registration and publication of } \\
\text { systematic review protocols and is available at the following link: } \\
\text { https://www.crd.york.ac.uk/PROSPERO/. } \\
\text { 4. We have now added a search strategy/example of Boolean } \\
\text { operator. Also copied on the last page of this response letter. }\end{array}$ \\
\hline
\end{tabular}




\begin{tabular}{|l|l|}
\hline $\begin{array}{l}\text { readership. A course at this year's EAU in London revealed that } \\
\text { this is a stumbling block for some novice researchers. }\end{array}$ & 5. We have now added: \\
How many cases/what percentage of cases would the authors \\
recommend as a pilot for data extraction?
\end{tabular}

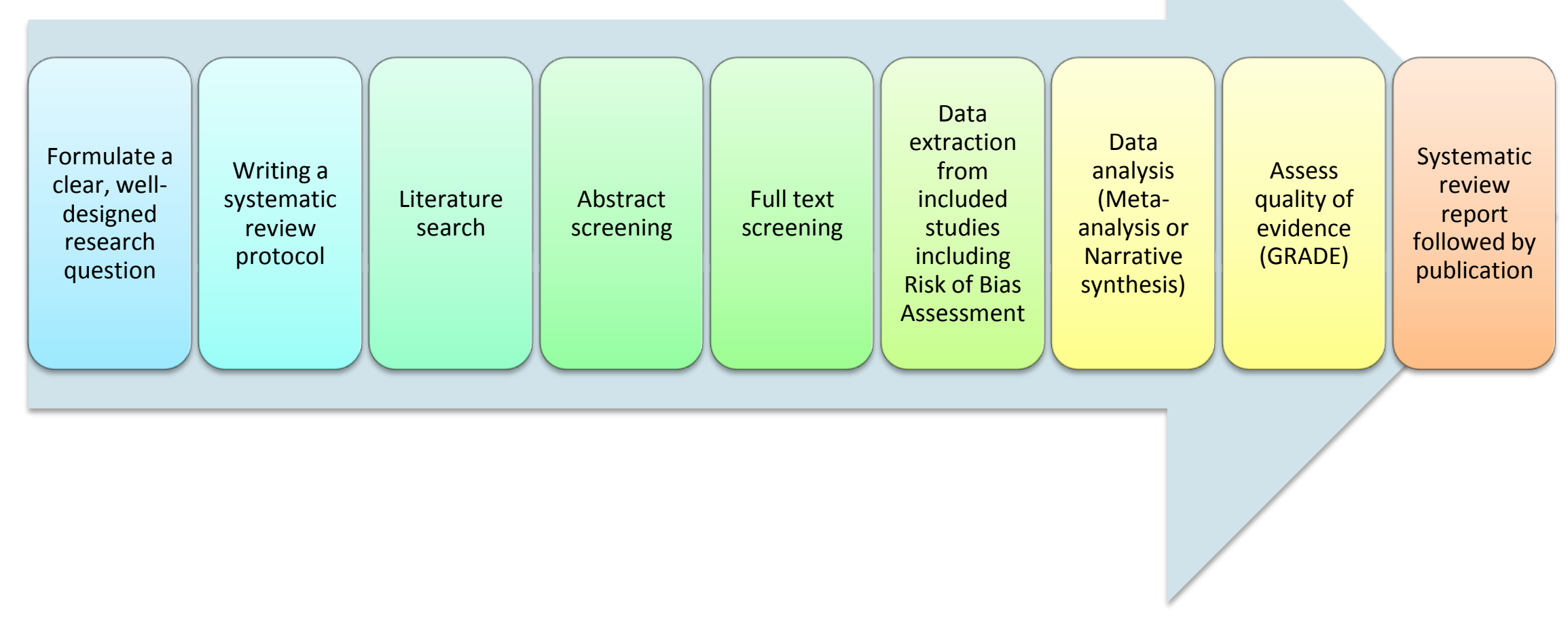

Figure 1: The process of conducting systematic review 


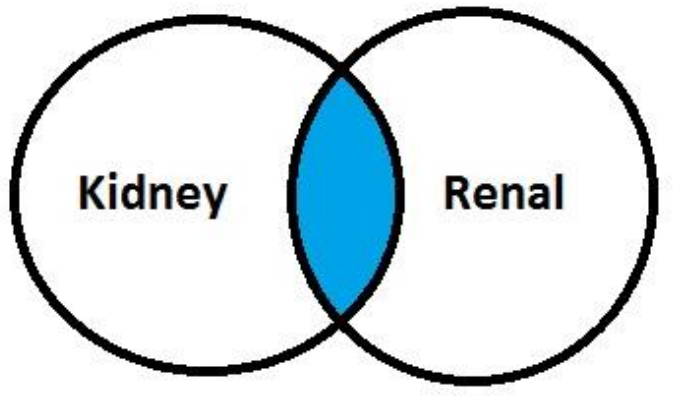

AND

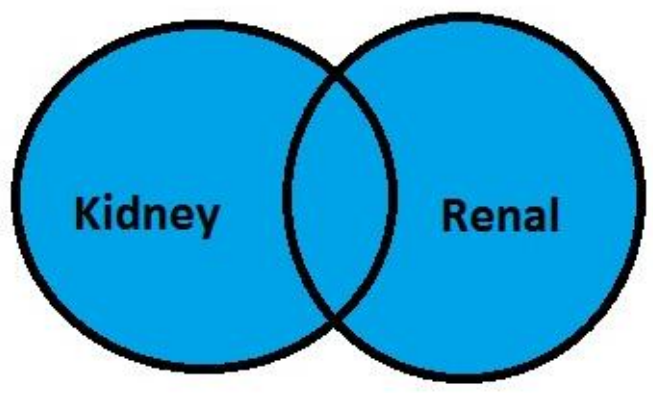

OR

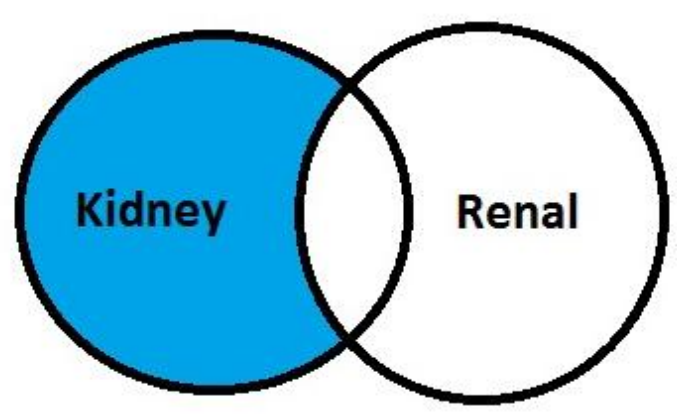

NOT

(To narrow search-both terms)

(To expend search i.e. either term)

(Eliminate-Only one term)

\begin{tabular}{|c|l|}
\hline Search strategy & Explanation \\
\hline $\begin{array}{l}\text { This will retrieve records with the word "kidney" or "renal" in the title } \\
\text { or abstract. }\end{array}$ & $\begin{array}{l}\text { This will retrieve records that have used the word related to cancer and } \\
\text { the synonyms and variations of root words, such as carcinoma(s), } \\
\text { malignant, malignancy, malignancies, tumor, tumour, neoplasm(s), } \\
\text { neoplastic, etc. }\end{array}$ \\
\hline $\begin{array}{l}\text { 2. } \quad \text { (cancer* or carcin* or malignan* or tumor* or tumour* or } \\
\text { neoplas*).ti,ab. }\end{array}$ & $\begin{array}{l}\text { This search string combines terms related to kidney and cancer and will } \\
\text { identify all records mentioning both terms in the titles or abstracts. }\end{array}$ \\
\hline 3. 1 and 2 & $\begin{array}{l}\text { This will identify records that tagged with the Medical Subject Heading } \\
\text { (MeSH) term "kidney neoplasms" (exploded) }\end{array}$ \\
\hline 5. 3 or 4 & $\begin{array}{l}\text { This will retrieve records related to kidney cancer using text words as } \\
\text { well as the MeSH term. }\end{array}$ \\
\hline 6. exp animals/ not humans/ & $\begin{array}{l}\text { This will retrieve records tagged with the MeSH term "animals"; } \\
\text { records that tagged with both animals and humans MeSH terms will } \\
\text { not be captured. }\end{array}$ \\
\hline 7. 5 not 6 & $\begin{array}{l}\text { This will retrieve records related to kidney cancer, excluding animal } \\
\text { records. }\end{array}$ \\
\hline
\end{tabular}

Figure 2: Example of search strategy 


\begin{tabular}{|c|c|}
\hline $\begin{array}{l}\text { Published systematic reviews conducted under the auspices of the EAU Guidelines } \\
\text { Office }\end{array}$ & Guideline recommendation(s) underpinned by this SR \\
\hline $\begin{array}{l}\text { Sylvester RJ, Oosterlinck W, Holmang S, Sydes MR, Birtle A, Gudjonsson S, et al. Systematic } \\
\text { Review and Individual Patient Data Meta-analysis of Randomized Trials Comparing a Single } \\
\text { Immediate Instillation of Chemotherapy After Transurethral Resection with Transurethral } \\
\text { Resection Alone in Patients with Stage pTa-pT1 Urothelial Carcinoma of the Bladder: Which } \\
\text { Patients Benefit from the Instillation? Eur Urol. 2016;69:231-44. }\end{array}$ & $\begin{array}{l}2016 \text { NMIBC Guidelines } \\
2017 \text { NMIBC Guidelines: Table 7.6, page 30, treatment of low risk and a } \\
\text { subgroup of intermediate risk patients with a single immediate } \\
\text { instillation of chemotherapy after TURBT. }\end{array}$ \\
\hline $\begin{array}{l}\text { Viktor Soukup, Otakar Capoun, Daniel Cohen, Virginia Hernandez, Marek Babjuk, et al.. } \\
\text { Prognostic Performance and Reproducibility of the } 1973 \text { and 2004/2016 World Health } \\
\text { Organization Grading Classification Systems in Non-muscle-invasive Bladder Cancer: A } \\
\text { European Association of Urology Non-muscle Invasive Bladder Cancer Guidelines Panel } \\
\text { Systematic Review. Eur Urol 2017, in press }\end{array}$ & To appear in the 2018 NMIBC Guidelines \\
\hline $\begin{array}{l}\text { Hernández V, Espinos EL, Dunn J, MacLennan S, Lam T, Yuan Y, et al. .Oncological and } \\
\text { functional outcomes of sexual function-preserving cystectomy compared with standard radical } \\
\text { cystectomy in men: A systematic review. Urol Oncol. } 2017 \text { May 8. pii: S1078-1439(17)30184-9. } \\
\text { doi: } 10.1016 / \text { j.urolonc.2017.04.013. [Epub ahead of print] }\end{array}$ & $\begin{array}{l}\text { The majority of patients motivated to preserve their sexual function will } \\
\text { benefit from sexual-preserving techniques. LE } 2 \\
\text { None of the sexual-preserving techniques } \\
\text { (prostate/capsule/seminal/nerve sparing) have shown to be } \\
\text { superior and no particular technique can be recommended. LE } 2 \\
\text { Offer sexual-preserving techniques to men motivated to preserve their } \\
\text { sexual function since the majority will benefit. LE } 2 \text { GR B } \\
\text { Select patients based on: } \\
\text { - Organ-confined disease; } \\
\text { - Absence of any kind of tumour at the level of the prostate, prostatic } \\
\text { urethra or bladder neck. } \\
\text { LE } 2 . \text { GR A } \\
\text { Do not offer sexual-preserving cystectomy as standard therapy for } \\
\text { MIBC. GR C } \\
\text { Guideline year: } 2016\end{array}$ \\
\hline $\begin{array}{l}\text { Seisen T, Peyronnet B, Dominguez-Escrig JL, Bruins HM, Yuan CY, Babjuk M, et al.. Oncologic } \\
\text { Outcomes of Kidney-sparing Surgery Versus Radical Nephroureterectomy for Upper Tract } \\
\text { Urothelial Carcinoma: A Systematic Review by the EAU Non-muscle Invasive Bladder Cancer }\end{array}$ & $\begin{array}{l}\text { EAU guideline on Upper Urinary Tract Urothelial Carcinoma 2017, } \\
\text { chapter 7.1.1.4: } \\
\text { Offer kidney-sparing management as primary treatment option to }\end{array}$ \\
\hline
\end{tabular}

Page $\mathbf{7}$ of $\mathbf{1 1}$ 


\begin{tabular}{|c|c|}
\hline $\begin{array}{l}\text { Guidelines Panel. Eur Urol. } 2016 \text { Dec;70(6):1052-1068. doi: 10.1016/j.eururo.2016.07.014. } \\
\text { Epub } 2016 \text { Jul } 28 .\end{array}$ & patients with low-risk tumour and two functional kidneys \\
\hline $\begin{array}{l}\text { Bruins HM, Veskimae E, Hernandez V, Imamura M, Neuberger MM, Dahm P, et al.. The impact } \\
\text { of the extent of lymphadenectomy on oncologic outcomes in patients undergoing radical } \\
\text { cystectomy for bladder cancer: a systematic review. Eur Urol. } 2014 \text { Dec;66(6):1065-77. doi: } \\
\text { 10.1016/j.eururo.2014.05.031. Epub } 2014 \text { Jul } 26 .\end{array}$ & $\begin{array}{l}\text { EAU guideline Muscle-Invasive and Metastatic Bladder Cancer 2017, } \\
\text { chapter 7.4.7: } \\
\text { Perform a lymph node dissection as an integral part of cystectomy. }\end{array}$ \\
\hline $\begin{array}{l}\text { Hoen L', Ecclestone H, Blok BF, Karsenty G, Phé V, Bossier R, et al. Long-term effectiveness and } \\
\text { complication rates of bladder augmentation in patients with neurogenic bladder dysfunction: } \\
\text { A systematic review. Neurourol Urodyn. } 2017 \text { Feb } 7 \text {. doi: 10.1002/nau.23205. [Epub ahead of } \\
\text { print] }\end{array}$ & To appear in the 2018 NMIBC Guidelines \\
\hline $\begin{array}{l}\text { Phé V, Boissier R, Blok BF, Del Popolo G, Musco S, Castro-Diaz D, et al.. Continent } \\
\text { catheterizable tubes/stomas in adult neuro-urological patients: A systematic review. } \\
\text { Neurourol Urodyn. } 2017 \text { Jan 31. doi: 10.1002/nau.23213. [Epub ahead of print] }\end{array}$ & To appear in the 2018 NMIBC Guidelines \\
\hline $\begin{array}{l}\text { Gross T, Schneider MP, Bachmann LM, Blok BF, Groen J, Hoen LA, et al.. Transcutaneous } \\
\text { Electrical Nerve Stimulation for Treating Neurogenic Lower Urinary Tract Dysfunction: A } \\
\text { Systematic Review. Eur Urol. } 2016 \text { Jun;69(6):1102-11. doi: 10.1016/j.eururo.2016.01.010. Epub } \\
2016 \text { Jan } 29 .\end{array}$ & $\begin{array}{l}\text { No Guideline recommendation but cited (Nbr 138) } \\
\text { 3.4.2.2.Neuro-urological rehabilitation } \\
\text { 3.4.2.2.1.Bladder rehabilitation including electrical stimulation } \\
\text { The term bladder rehabilitation summarises treatment options that aim } \\
\text { to re-establish bladder function in patients with neuro-urological } \\
\text { symptoms. Strong contraction of the urethral sphincter and/or pelvic } \\
\text { floor, as well as anal dilatation, manipulation of the genital region, and } \\
\text { physical activity inhibit micturition in a reflex manner [119, } 136] \text {. The } \\
\text { first mechanism is affected by activation of efferent nerve fibres, and } \\
\text { the latter ones are produced by activation of afferent fibres [98]. } \\
\text { Electrical stimulation of the pudendal nerve afferents strongly inhibits } \\
\text { the micturition reflex and detrusor contraction [137]. This stimulation } \\
\text { might then support the restoration of the balance between excitatory } \\
\text { and inhibitory inputs at the spinal or supraspinal level }[119,138] \text {. } \\
\text { Evidence for bladder rehabilitation using electrical stimulation in } \\
\text { neurological patients is mainly based on small non-comparative studies } \\
\text { with high risk of bias. } \\
\text { Peripheral temporary electrostimulation: Tibial nerve stimulation and } \\
\text { transcutaneous electrical nerve stimulation might be effective and safe } \\
\text { for treating neurogenic lower urinary tract dysfunction, but more }\end{array}$ \\
\hline
\end{tabular}

Page 8 of 11 


\begin{tabular}{|c|c|}
\hline & $\begin{array}{l}\text { reliable evidence from well-designed RCTs is required to reach definitive } \\
\text { conclusions }[138,139] \text {. }\end{array}$ \\
\hline $\begin{array}{l}\text { Schneider MP, Gross T, Bachmann LM, Blok BF, Castro-Diaz D, Del Popolo G, et al.. Tibial Nerve } \\
\text { Stimulation for Treating Neurogenic Lower Urinary Tract Dysfunction: A Systematic Review. } \\
\text { Eur Urol. } 2015 \text { Nov;68(5):859-67. doi: 10.1016/j.eururo.2015.07.001. Epub } 2015 \text { Jul } 18 .\end{array}$ & $\begin{array}{l}\text { No Guideline recommendation but cited (Nbr 139) } \\
\text { 3.4.2.2.Neuro-urological rehabilitation } \\
\text { 3.4.2.2.1.Bladder rehabilitation including electrical stimulation } \\
\text { The term bladder rehabilitation summarises treatment options that aim } \\
\text { to re-establish bladder function in patients with neuro-urological } \\
\text { symptoms. Strong contraction of the urethral sphincter and/or pelvic } \\
\text { floor, as well as anal dilatation, manipulation of the genital region, and } \\
\text { physical activity inhibit micturition in a reflex manner [119, } 136] \text {. The } \\
\text { first mechanism is affected by activation of efferent nerve fibres, and } \\
\text { the latter ones are produced by activation of afferent fibres [98]. } \\
\text { Electrical stimulation of the pudendal nerve afferents strongly inhibits } \\
\text { the micturition reflex and detrusor contraction [137]. This stimulation } \\
\text { might then support the restoration of the balance between excitatory } \\
\text { and inhibitory inputs at the spinal or supraspinal level [119, } 138] \text {. } \\
\text { Evidence for bladder rehabilitation using electrical stimulation in } \\
\text { neurological patients is mainly based on small non-comparative studies } \\
\text { with high risk of bias. } \\
\text { Peripheral temporary electrostimulation: Tibial nerve stimulation and } \\
\text { transcutaneous electrical nerve stimulation might be effective and safe } \\
\text { for treating neurogenic lower urinary tract dysfunction, but more } \\
\text { reliable evidence from well-designed RCTs is required to reach definitive } \\
\text { conclusions [138,139]. }\end{array}$ \\
\hline $\begin{array}{l}\text { Sujenthiran A, Elshout PJ, Veskimäe E, MacLennan S, Yan Y, Serafetinidis E, et al.. Is non- } \\
\text { operative management the best first-line option for high-grade renal trauma? A systematic } \\
\text { review. European Urology Focus } 2017 \text { May 29; doi:10.1016/j.euf.2017.04.011 }\end{array}$ & $\begin{array}{l}\text { Urogenital Trauma Guidelines 2017; Ch 4.1.3.1.1. Blunt renal injuries; LE } \\
\text { 3, GR B }\end{array}$ \\
\hline $\begin{array}{l}\text { Elshout PJ, Veskimae E, MacLennan S, Yuan Y, Lumen N, Gonsalves M, et al.. Outcomes of Early } \\
\text { Endoscopic Realignment Versus Suprapubic Cystostomy and Delayed Urethroplasty for Pelvic } \\
\text { Fracture-related Posterior Urethral Injuries: A Systematic Review. European Urology Focus } \\
2017 \text { Mar 6; doi: 10.1016/j.euf.2017.03.001 }\end{array}$ & $\begin{array}{l}\text { Urogenital Trauma Guidelines 2017; Ch 4.4.1.2.2. Posterior urethral } \\
\text { injuries (in males). LE 2a, GR B }\end{array}$ \\
\hline $\begin{array}{l}\text { Veskimäe E, Nezuillet Y, Rouanne M, MacLennan S, Lam T, Yuan Y, et al.. What are the } \\
\text { oncological and functional outcomes of pelvic organ-preserving crstectomy compared with }\end{array}$ & $\begin{array}{l}\text { MIBC 2017; Ch 7.4.3.2. Pelvic organ preservation techniques in women: } \\
\text { oncological and functional outcomes; LE 3, GR C; new chapter based on }\end{array}$ \\
\hline
\end{tabular}




\begin{tabular}{|c|c|}
\hline $\begin{array}{l}\text { standard radical cystectomy in women with bladder cancer and a neobladder? Systematic } \\
\text { review. BJU Int. } 2017 \text { Feb 20. doi: 10.1111/bju.13819 }\end{array}$ & the review \\
\hline $\begin{array}{l}\text { Ruhayel Y, Tepeler A, Dabestani S, MacLennan S, Petř́k A, Sarica K, et al.. Tract Sizes in } \\
\text { Miniaturized Percutaneous Nephrolithotomy: A Systematic Review from the European } \\
\text { Association of Urology Urolithiasis Guidelines Panel. Eur Urol. 2017 Aug;72(2):220-235. doi: } \\
\text { 10.1016/j.eururo.2017.01.046. Epub } 2017 \text { Feb 23. PubMed PMID: 28237786. }\end{array}$ & $\begin{array}{l}\text { Guideline on Urolithiasis } 2016 \text { onwards } \\
\text { Statement on tract sizes for percutaneous nephrolithotomy }\end{array}$ \\
\hline $\begin{array}{l}\text { Drake T, Grivas N, Dabestani S, Knoll T, Lam T, Maclennan S, et al. What are the Benefits and } \\
\text { Harms of Ureteroscopy Compared with Shock-wave Lithotripsy in the Treatment of Upper } \\
\text { Ureteral Stones? A Systematic Review. Eur Urol. } 2017 \text { Apr 26. pii:S0302-2838(17)30324-X. doi: } \\
\text { 10.1016/j.eururo.2017.04.016. [Epub ahead of print] Review. PubMed PMID: 28456350. }\end{array}$ & $\begin{array}{l}\text { Guideline on Urolithiasis } 2016 \text { onwards } \\
\text { Recommendations on inventional treatment for upper ureteral calculi }\end{array}$ \\
\hline $\begin{array}{l}\text { Preminger GM, Tiselius HG, Assimos DG, Alken P, Buck AC, Gallucci M, et al.; American } \\
\text { Urological Association Education and Research, Inc; European Association of } \\
\text { Urology. 2007 Guideline for the management of ureteral calculi. Eur Urol. } 2007 \\
\text { Dec;52(6):1610-31. PubMed PMID: } 18074433 .\end{array}$ & $\begin{array}{l}\text { Guideline on Urolithiasis } 2008 \text { onwards until update in } 2016 \\
\text { Recommendations and statements on management of ureteral calculi }\end{array}$ \\
\hline $\begin{array}{l}\text { Silay MS, Undre S, Nambiar AK, Dogan HS, Kocvara R, et al.. Role of antibiotic prophylaxis in } \\
\text { antenatal hydronephrosis: A systematic } \\
\text { review from the European Association of Urology/European Society for Paediatric } \\
\text { Urology Guidelines Panel. J Pediatr Urol. } 2017 \text { Jun;13(3):306-315. doi: } \\
\text { 10.1016/j.jpurol.2017.02.023. Epub } 2017 \text { Mar 19. }\end{array}$ & $\begin{array}{l}\text { In children diagnosed with antenatal hydronephrosis, a systematic } \\
\text { review could not establish any benefits or harms related to continuous } \\
\text { antibiotic prophylaxis. (1b) } \\
\text { In children diagnosed with antenatal hydronephrosis, non-circumcised } \\
\text { infants (LE: 1a), children diagnosed with high-grade hydronephrosis (LE: } \\
\text { 2) and hydroureteronephrosis (LE: } 1 \text { b) were shown to be at higher risk } \\
\text { of developing UTI. }\end{array}$ \\
\hline $\begin{array}{l}\text { Malde S, Nambiar AK, Umbach R, Lam TB, Bach T, et al. Systematic Review of the } \\
\text { Performance of Noninvasive Tests in Diagnosing Bladder Outlet Obstruction in Men with } \\
\text { Lower Urinary Tract Symptoms. Eur Urol. } 2017 \text { Mar;71(3):391-402. doi: } \\
\text { 10.1016/j.eururo.2016.09.026. Epub 2016 Sep } 2\end{array}$ & $\begin{array}{l}\text { None of the non-invasive tests in diagnosing bladder outlet obstruction } \\
\text { in men with LUTS can currently be recommended as an alternative to } \\
\text { pressure-flow studies. Grade B }\end{array}$ \\
\hline $\begin{array}{l}\text { Marconi L, Dabestani S, Lam TB, Hofmann F, Stewart F, Norrie J, et al. Systematic Review and } \\
\text { Meta-analysis of Diagnostic Accuracy of Percutaneous Renal Tumour Biopsy. Eur Urol. } 2016 \\
\text { Apr;69(4):660-73. doi: 10.1016/j.eururo.2015.07.072. Epub } 2015 \text { Aug 29. }\end{array}$ & $\begin{array}{l}\text { 1. Use a coaxial technique when performing a renal tumour biopsy. } \\
\text { strong } \uparrow \uparrow \\
\text { 2. Do not perform a renal tumour biopsy of cystic renal masses. weak } \downarrow \\
\text { 3. Perform a percutaneous biopsy in select patients who are considered } \\
\text { for active surveillance. weak } \uparrow \text { (This recommendation was indirectly } \\
\text { derived from the Systematic Review) }\end{array}$ \\
\hline $\begin{array}{l}\text { 't Hoen LA, Groen J, Scheepe JR, Reuvers S, Diaz DC, Fernández BP, et al. A Quality Assessment } \\
\text { of Patient-Reported Outcome Measures for Sexual Function in Neurologic Patients Using the } \\
\text { Consensus-based Standards for the Selection of Health Measurement Instruments Checklist: A }\end{array}$ & To appear in the 2018 Guidelines. \\
\hline
\end{tabular}

Page $\mathbf{1 0}$ of $\mathbf{1 1}$ 


\begin{tabular}{|c|c|}
\hline $\begin{array}{l}\text { Systematic Review. Eur Urol Focus. } 2016 \text { Jun 23. pii: S2405-4569(16)30069-4. doi: } \\
\text { 10.1016/j.euf.2016.06.009. [Epub ahead of print] }\end{array}$ & \\
\hline $\begin{array}{l}\text { Moldovan PC, Van den Broeck T, Sylvester R, Marconi L, Bellmunt J, van den Bergh RCN, et al. } \\
\text { What Is the Negative Predictive Value of Multiparametric Magnetic Resonance Imaging in } \\
\text { Excluding Prostate Cancer at Biopsy? A Systematic Review and Meta-analysis from the } \\
\text { European Association of Urology Prostate Cancer Guidelines Panel. Eur Urol (2017), } \\
\text { http://dx.doi.org/10.1016/j.eururo.2017.02.026 }\end{array}$ & To appear in the 2018 Guidelines \\
\hline $\begin{array}{l}\text { Sakalis } \mathrm{V}^{1} \text {, Karavitakis M, Bedretdinova D, Bach T, Bosch JLHR, Gacci M, et al. Medical } \\
\text { Treatment of Nocturia in Men with Lower Urinary Tract Symptoms: Systematic Review by the } \\
\text { European Association of Urology Guidelines Panel for Male Lower Urinary Tract Symptoms. Eur } \\
\text { Urol. } 2017 \text { Jun 27. pii: S0302-2838(17)30505-5. doi: 10.1016/j.eururo.2017.06.010. [Epub } \\
\text { ahead of print] }\end{array}$ & To appear in the 2018 Guidelines \\
\hline $\begin{array}{l}\text { Fossati N, Willemse PM, Van den Broeck T, van den Bergh RCN, Yuan CY, Briers E, et al. The } \\
\text { Benefits and Harms of Different Extents of Lymph Node Dissection During Radical } \\
\text { Prostatectomy for Prostate Cancer: A Systematic Review. Eur Urol. } 2017 \text { Jul;72(1):84-109. doi: } \\
\text { 10.1016/j.eururo.2016.12.003. Epub } 2017 \text { Jan } 24 .\end{array}$ & To appear in the 2018 Guidelines \\
\hline
\end{tabular}

Table A: Guideline recommendation(s) underpinned by the selected SRs conducted under the auspices of the EAU Guidelines Office. 